\title{
Supramolecular arrangement of protein in nanoparticle structures predicts nanoparticle tropism for neutrophils in acute lung inflammation
}

\author{
Jacob W. Myerson ${ }^{1,8}$, Priyal N. Patel ${ }^{1,8}$, Kathryn M. Rubey ${ }^{\circledR 2,8}$, Marco E. Zamora ${ }^{1}$, Michael H. Zaleski ${ }^{1}$, \\ Nahal Habibi ${ }^{3}$, Landis R. Walsh', Yi-Wei Lee ${ }^{4}$, David C. Luther ${ }^{4}$, Laura T. Ferguson ${ }^{1,5}$, \\ Oscar A. Marcos-Contreras', Patrick M. Glassman ${ }^{1}{ }^{1}$, Liudmila L. Mazaleuskaya ${ }^{1,6}$, Ian Johnston?', \\ Elizabeth D. Hood', Tea Shuvaeva ${ }^{\circledR 1}$, Jichuan Wu', Hong-Ying Zhang1, Jason V. Gregory $\mathbb{D}^{3}$, \\ Raisa Y. Kiseleva1, Jia Nong1, Tilo Grosser ${ }^{1,6}$, Colin F. Greineder1, Samir Mitragotri ${ }^{7}$, George S. Worthen², \\ Vincent M. Rotello $\mathbb{1}^{4}$, Joerg Lahann $\mathbb{1}^{3}$, Vladimir R. Muzykantov' and Jacob S. Brenner $\mathbb{1}$ 1,5凶
}

This study shows that the supramolecular arrangement of proteins in nanoparticle structures predicts nanoparticle accumulation in neutrophils in acute lung inflammation (ALI). We observed homing to inflamed lungs for a variety of nanoparticles with agglutinated protein (NAPs), defined by arrangement of protein in or on the nanoparticles via hydrophobic interactions, crosslinking and electrostatic interactions. Nanoparticles with symmetric protein arrangement (for example, viral capsids) had no selectivity for inflamed lungs. Flow cytometry and immunohistochemistry showed NAPs have tropism for pulmonary neutrophils. Protein-conjugated liposomes were engineered to recapitulate NAP tropism for pulmonary neutrophils. NAP uptake in neutrophils was shown to depend on complement opsonization. We demonstrate diagnostic imaging of ALI with NAPs; show NAP tropism for inflamed human donor lungs; and show that NAPs can remediate pulmonary oedema in ALI. This work demonstrates that structure-dependent tropism for neutrophils drives NAPs to inflamed lungs and shows NAPs can detect and treat ALI.

$\mathrm{N}$ eutrophils are 'first-responder' cells in acute inflammation, rapidly 'marginating' in and adhering to inflamed vessels ${ }^{1-7}$. Neutrophils can be activated by a variety of pathogen- and damage-associated factors, such as bacterial lipopolysaccharides (LPS $)^{8,9}$. In acute inflammation, neutrophils marginate in most organs, but by far most avidly in the lung capillaries. There, abundant narrow vessels provide an ideal setting for neutrophil accumulation by adhesion and by mechanical retention aided by changes in neutrophil stiffness during inflammation ${ }^{5,6,10-15}$. Neutrophils are therefore key cell types in acute lung inflammation (ALI). In ALI, marginated neutrophils can secrete tissue-damaging substances (proteases, reactive oxygen species) and extravasate into alveoli, leading to a disrupted endothelial barrier and accumulation of neu-

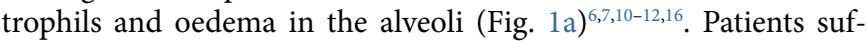
fering the worst outcomes in COVID-19 have elevated neutrophil counts and neutrophilic infiltration in the alveoli ${ }^{17-19}$.

One of the challenges of treating ALI with drugs is poor tolerance of side effects in patients with the severe and heterogeneous system-wide maladies that can lead to $\mathrm{ALI}^{20-23}$. Targeted nanoparticle delivery to marginated neutrophils could provide treatment with lessened side effects, but delivery to marginated neutrophils remains an open challenge. Antibodies against Ly6G have achieved targeting to neutrophils in mice, but also deplete circulating neutrophils $^{24-27}$. Additionally, while Ly6G marks neutrophils in mice, there is no analogous specific and ubiquitous marker on human neutrophils ${ }^{24}$. Therefore, antibody targeting has not been widely adopted for targeted drug delivery to neutrophils ${ }^{26}$. As another route to neutrophil targeting, previous studies observed activated neutrophils take up denatured and crosslinked albumin, concluding that denatured protein is critical in neutrophil-nanoparticle interactions ${ }^{28,29}$.

Nanoparticle structural properties such as shape, size and surface charge can define targeting behaviours ${ }^{30-34}$. In this article we screened a diverse panel of nanoparticles to identify structural properties that predict nanoparticle uptake in pulmonary marginated neutrophils in ALI. We identified more than ten nanoparticles with high selectivity for inflamed over naive lungs. Flow cytometry and immunohistochemistry showed these nanoparticles homing to marginated neutrophils. In many of the nanoparticles we tested, proteins were arranged at the supramolecular scale by different engineered intermolecular interactions or by evolved highly symmetrical arrangements of proteins (for example, viral capsids). Each nanoparticle with selectivity for inflamed lungs had structures with

'Department of Systems Pharmacology and Translational Therapeutics, Perelman School of Medicine, University of Pennsylvania, Philadelphia, PA, USA. 2Department of Pediatrics, Perelman School of Medicine, University of Pennsylvania, Philadelphia, PA, USA. ${ }^{3}$ Biointerfaces Institute and Department of Chemical Engineering, University of Michigan at Ann Arbor, Ann Arbor, MI, USA. ${ }^{4}$ Department of Chemistry, University of Massachusetts at Amherst, Amherst, MA, USA. ${ }^{5}$ Pulmonary, Allergy, and Critical Care Division, Department of Medicine, Perelman School of Medicine, University of Pennsylvania, Philadelphia, PA, USA. 'Institute for Translational Medicine and Therapeutics, Perelman School of Medicine, University of Pennsylvania, Philadelphia, PA, USA. ${ }^{7}$ John A Paulson School of Engineering \& Applied Sciences and Wyss Institute, Harvard University, Cambridge, MA, USA. ${ }^{8}$ These authors contributed

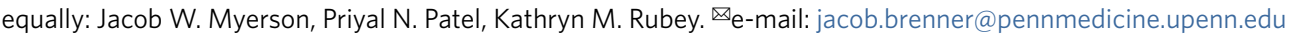


agglutinated protein in or on the nanoparticle. Nanoparticles with agglutinated protein (NAPs) are defined here as nanoparticles with supramolecular arrangement of protein in or on the nanoparticles determined by hydrophobic interactions, non-site-specific crosslinking or electrostatic interactions. In contrast to NAPs, we found that viral capsids and ferritin nanocages, defined by a regularly spaced and symmetric protein arrangement, have no selectivity for inflamed lungs. This study therefore shows that supramolecular arrangement of protein in nanoparticle structure predicts nanoparticle uptake in neutrophils in ALI. Our findings show that NAPs may improve diagnosis and treatment of acute lung inflammation.

\section{Injury-selective uptake of nanoparticles in marginated neutrophils}

Tracing of radiolabelled anti-Ly6G antibody, flow cytometry data and histology showed that intravenous (i.v.) LPS challenge in mice induces neutrophil margination in pulmonary vasculature $5 \mathrm{~h}$ after LPS administration (Supplementary Figs. 1 and 2). Following i.v. LPS, tracing of radiolabelled, fixed and inactivated Escherichia coli indicated marginated neutrophils in the lungs taking up the bacteria (Supplementary Fig. 3). To identify parameters in nanoparticle structure that correlate with nanoparticle uptake in marginated neutrophils in inflamed lungs, we therefore conducted an in vivo screen of biodistributions for a diverse array of radiolabelled nanoparticles in naive and i.v.-LPS-challenged mice. To show the radiotracer screen measures nanoparticle uptake in pulmonary marginated neutrophils, we more fully characterized the in vivo behaviour of two early hits in the screen.

Lysozyme-dextran nanogels (NGs) and poly(ethylene)glycol (PEG)-crosslinked albumin nanoparticles (albumin NPs) have been characterized as targeted drug-delivery agents ${ }^{35-38} \cdot{ }^{125} \mathrm{I}$-Labelled NGs (diameter, $136.4 \pm 3.6 \mathrm{~nm}$; polydispersity index (PDI), $0.10 \pm 0.02$; zeta potential, $-0.3 \pm 0.1 \mathrm{mV}$; Supplementary Fig. $4 \mathrm{a})$ and human albumin NPs (diameter, $317.8 \pm 3.6 \mathrm{~nm}$; PDI, $0.14 \pm 0.05$; zeta potential, $-13.6 \pm 0.6 \mathrm{mV}$; Supplementary Fig. $4 \mathrm{~b}$ ) were traced $30 \mathrm{~min}$ after i.v. injection in naive and i.v.-LPS-injured mice. Absolute NG lung uptake and lung:liver ratio increased 25 -fold between naive and LPS-injured animals (Fig. 1b and Supplementary Table 2). Lung uptake of human albumin NPs increased 14-fold (Fig. 1c and Supplementary Table 2). Pharmacokinetics studies showed that NG uptake in inflamed lungs peaked $30 \mathrm{~min}$ after injection, followed by clearance over 24h (Supplementary Fig. 5).

Flow cytometry identified cell types taking up fluorescent NGs or albumin NPs in the lungs. Flow data showed that the total number of lung cells containing NGs or albumin NPs increased between naive and LPS-injured lungs, corroborating radiotracer findings (Supplementary Figs. 5 and 6). Neutrophils accounted for the bulk of NG and albumin nanoparticle accumulation in i.v.-LPS-injured lungs (Fig. 1d,e). More than $70 \%$ of neutrophils contained nanoparticles in LPS-affected lungs, compared with $<20 \%$ in naive lungs. Likewise, more than $70 \%$ of nanoparticle uptake in the lungs was accounted for by uptake in neutrophils (Fig. 1f-i and Supplementary Table 3). Leukocytes in general accounted for more than $90 \%$ of nanoparticle uptake (Supplementary Fig. 6c,d). Histology of LPS-injured lungs confirmed NG localization to neutrophils in lung vasculature (Fig. 1j). Slices in confocal images indicated that NGs were inside neutrophils (Fig. 1k). Intravital imaging of injured lungs showed real-time colocalizing of NGs with leukocytes in injured lungs (Fig. 11 and Supplementary Movie 1).

NGs accumulated in neutrophils in other models. Radiolabelled NGs also accumulated in the lungs following intratracheal (i.t. ${ }^{39}$ and footpad LPS administration ${ }^{40}$. Lung:liver NG uptake ratio increased 45-fold following i.t.-LPS injury (Supplementary Fig. 8). Footpad LPS induced an 11-fold increase in NG lung uptake $6 \mathrm{~h}$ after insult and a 38-fold increase at $24 \mathrm{~h}$ (Supplementary Fig. 9). Footpad LPS also enhanced NG uptake in the legs. Intraplantar complete Freund's adjuvant (CFA) injection was used to induce acute neutrophil accumulation local to the footpad, rather than the lungs ${ }^{41,42}$. CFA injury led to a threefold increase in NG uptake in the ipsilateral paw, but no change in lung uptake (Supplementary Fig. 10 ). Flow cytometry showed that $\sim 90 \%$ of NG uptake in the feet was in leukocytes. CFA induced a fourfold increase in the proportion of NG uptake accounted for by neutrophils, demonstrating NG tropism for neutrophils outside of the lungs (Supplementary Fig. 11).

\section{In vivo screen of diverse nanoparticle structures in acutely inflamed lungs}

We screened biodistributions of nanoparticles with different sizes, shapes, compositions and surface charges in naive and i.v.-LPS-challenged mice. A subset of these nanoparticles had structures incorporating protein, including variant NGs (nanoparticles based on hydrophobic interactions between proteins), crosslinked protein nanoparticles, nanoparticles based on electrostatic interactions of charged proteins, viral capsids and ferritin nanocages.

Nanoparticles based on hydrophobic protein interactions. Atomic force microscopy and electron microscopy studies have shown that NGs form by lysozyme-lysozyme hydrophobic interactions, arranging a protein core stabilized by a dextran shell ${ }^{35,37,43}$. Noting previous work implicating denatured protein as a factor in nanoparticle uptake in neutrophils ${ }^{28,29}$, we obtained circular dichroism (CD) spectroscopy data indicating that the secondary structure of lysozyme in NGs is the same as lysozyme itself (Supplementary Fig. 12a). Lysozyme and NGs were exposed to the hydrophobic

Fig. 1 | Lysozyme-dextran NGs and crosslinked albumin NPs accumulate in marginated neutrophils in inflamed lungs. a, Schematic of neutrophil margination and extravasation in inflamed lungs (created with BioRender.com). ROS, reactive oxygen species. b, Biodistributions of lysozyme-dextran NGs in naive ( $n=4$ animals) and i.v.-LPS-affected ( $n=8$ animals) male C57BL/6 mice (red box, $\left.P<1 \times 10^{-10} ;{ }^{\star} P=0.00008\right)$. Inset: ratio of nanoparticle uptake in the lungs to nanoparticle uptake in the liver. $\mathbf{c}$, Biodistributions of PEG- $N$-hydroxysuccinimide crosslinked human albumin NPs in naive ( $n=3$ animals) and i.v.-LPS-injured ( $n=3$ animals) mice (red box, $\left.P<1 \times 10^{-10} ;{ }^{\star} P=0.004\right)$. Inset: ratio of nanoparticle uptake in the lungs to nanoparticle uptake in the liver. $\mathbf{d}-\mathbf{k}$, Flow cytometry characterization of single-cell suspensions prepared from naive and i.v.-LPS-affected mouse lungs. Vertical axis in $\mathbf{d}$ and $\mathbf{e}$ indicates Ly6G staining for neutrophils and horizontal axis indicates signal from fluorescent NGs (d) or fluorescent albumin NPs (e). NG (f) and albumin NP (i) fluorescent signal from neutrophils in i.v.-LPS-injured mouse lungs (red/pink), compared to naive lungs (blue). Insets in $\mathbf{f}$ and $\mathbf{i}$ : flow cytometry data verifying increased neutrophil concentration in i.v.-LPS-injured mouse lungs (red/pink). Fraction of neutrophils positive for NGs (g) or albumin NPs (j) in naive or i.v.-LPS-injured lungs and fraction of NG-positive (h) or albumin NP-positive (k) cells that are neutrophils. For $\mathbf{g}$ and $\mathbf{h}, \mathrm{NGs} / \mathrm{naive:} n=4$ animals, NGs/LPS: $n=4$ animals. For $\mathbf{j}$ and $\mathbf{k}$, albumin NPs/naive: $n=3$ animals, albumin NPs/LPS: $n=3$ animals. ${ }^{\star} P=2.6 \times 10^{-7}(\mathbf{g}),{ }^{\star} P=1.7 \times 10^{-5}(\mathbf{h})$, ${ }^{\star} P=0.0006(\mathbf{j}),{ }^{\star} P=0.007(\mathbf{k})$. For $\mathbf{I}$ and $\mathbf{m}$, fluorescence micrographs indicating association of NGs (red) with neutrophils (green, Ly6G stain) in the lungs of an i.v.-LPS-affected mouse (blue, tissue autofluorescence). Data are from histology for two naive mice and two i.v.-LPS-affected mice. I, Broad field of view indicating neutrophils and NGs alongside lung anatomy. $\mathbf{m}$, Narrow field of view showing two neutrophils containing NGs. $\mathbf{n}$, Single frame from real-time intravital imaging of NG (red) uptake in leukocytes (green) in the lungs of one i.v.-LPS-affected mouse (blue, Alexa Fluor 647-dextran). Statistical significance in $\mathbf{b}$ and $\mathbf{c}$ is derived from two-way analysis of variance (ANOVA) with Sidak's multiple-comparisons test. Statistical significance in $\mathbf{g}$,h,j,k is derived from paired two-tailed $t$ tests. All error bars indicate mean \pm s.e.m. 
probe 8-anilino-1-naphthalenesulfonic acid (ANSA) ${ }^{44}$, demonstrating increased hydrophobicity on NGs versus lysozyme itself (Supplementary Fig. 12b). Our data are not consistent with lysozyme being denatured in NGs, but lysozyme arrangement in NGs alters the accessibility of hydrophobic domains.

NG structure was varied by modifying the lysozyme-dextran composition and the $\mathrm{pH}$ at which NGs were formed ${ }^{43}$. NGs of diameter $\sim 75 \mathrm{~nm}$ (zeta potential, $7.1 \pm 0.5 \mathrm{mV}$ ), $\sim 200 \mathrm{~nm}$ (zeta potential, $-0.2 \pm 0.2 \mathrm{mV}$ ) and $\sim 275 \mathrm{~nm}$ (zeta potential, $-0.4 \pm 0.1 \mathrm{mV}$ ) were traced, adding to data above for $130 \mathrm{~nm}$ NGs (Supplementary
Figs. 4a and 13 and Supplementary Table 1). All the NG variants had consistent uptake in inflamed lungs, despite size-dependent variations in NG uptake in the liver and spleen (Fig. 2a and Supplementary Table 4).

Nanoparticlesbased on protein crosslinking. Electrohydrodynamic jetting has been used to form highly monodisperse PEG-crosslinked albumin micro- and nanoparticles, as characterized in electron microscopy studies ${ }^{38,45-47}$. CD spectroscopy indicated that albumin secondary structure was not altered in albumin NPs, while ANSA a

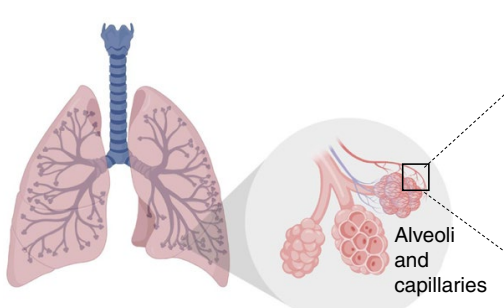

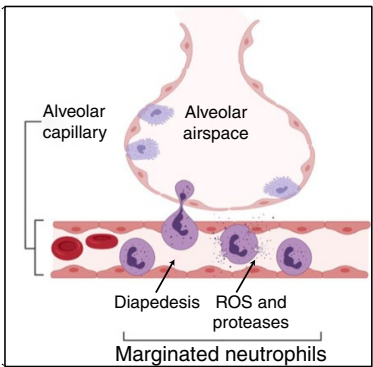
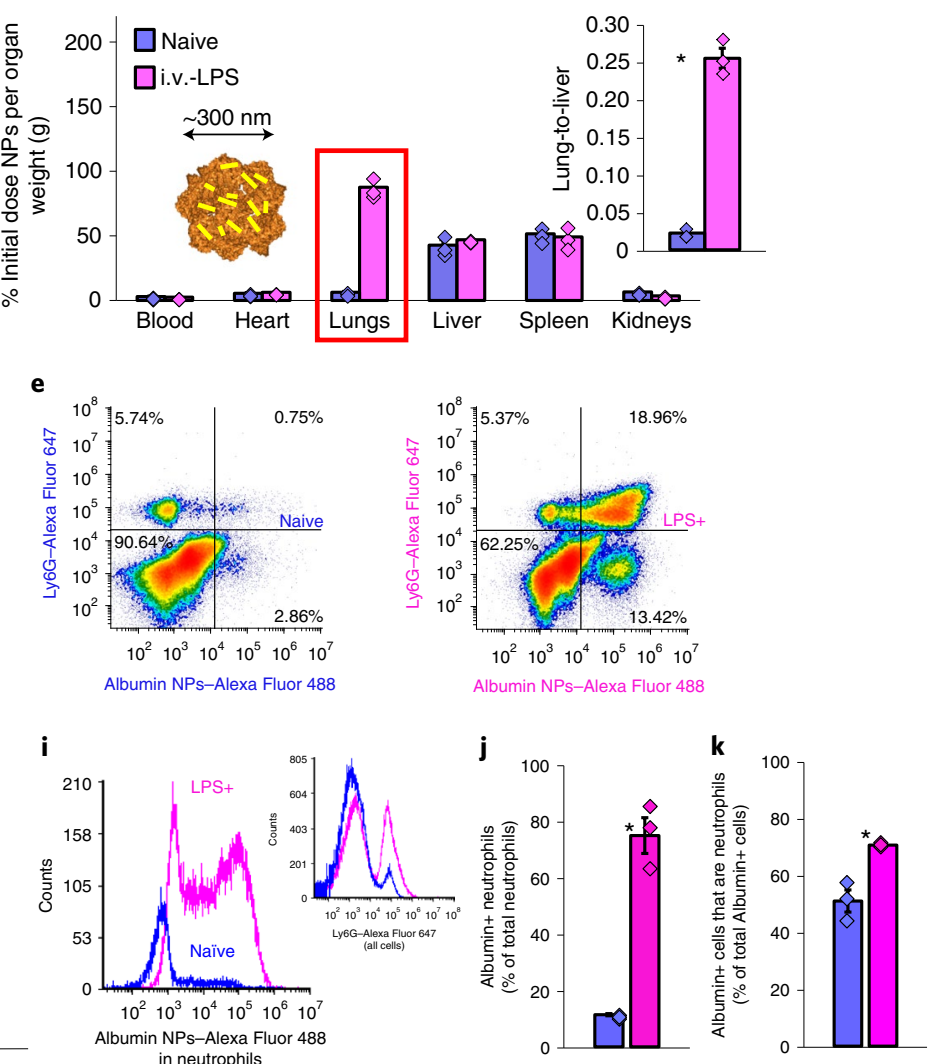

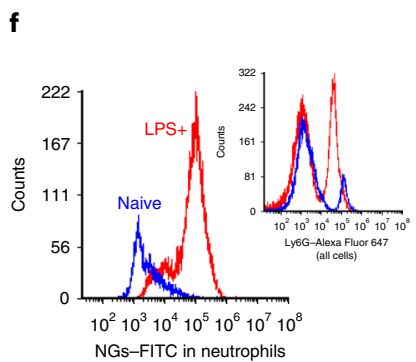

I

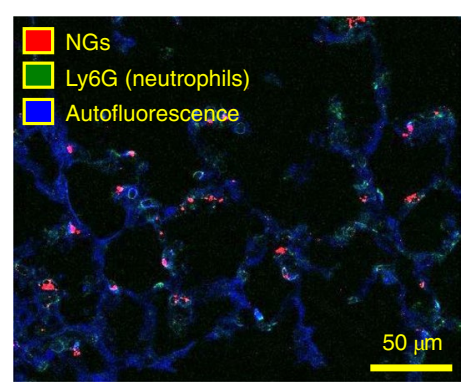

g

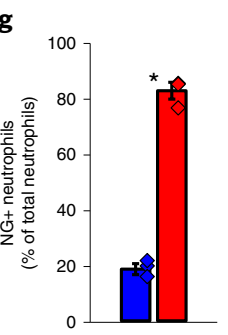

h

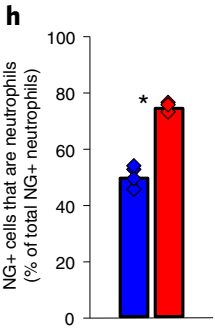

i

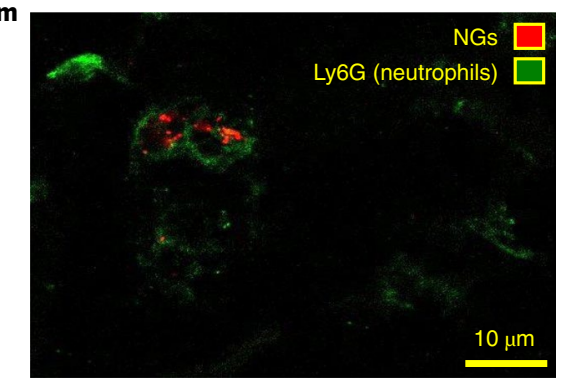

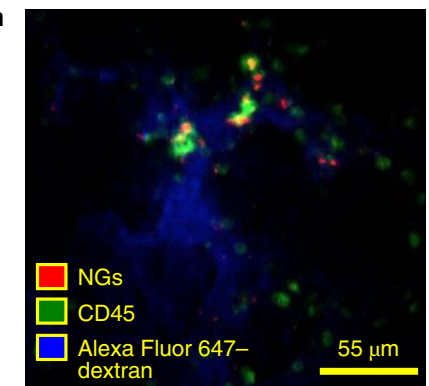


staining indicated that PEG-albumin NPs are more hydrophilic than albumin alone (Supplementary Fig. 14).

We varied the geometry and protein composition of crosslinked protein nanoparticles. Human albumin nanorods (aspect ratio, 3:1), bovine albumin nanoparticles $(317.3 \pm 38.5 \mathrm{~nm}$; PDI, $0.17 \pm 0.04$; zeta potential, $-11.2 \pm 0.5 \mathrm{mV})$, human haemoglobin nanoparticles $(328.1 \pm 16.1 \mathrm{~nm}$; PDI, $0.08 \pm 0.01$; zeta potential, $-6.6 \pm 0.8$ $\mathrm{mV})$, human transferrin nanoparticles $(345.2 \pm 10.2 \mathrm{~nm}$; PDI, $0.12 \pm 0.004$; zeta potential, $-5.6 \pm 0.8 \mathrm{mV}$ ) and chicken lysozyme nanoparticles $(298.6 \pm 12.4 \mathrm{~nm}$; PDI, $0.06 \pm 0.01$; zeta potential, $-0.2 \pm 0.7 \mathrm{mV}$ ) were traced in naive and IV LPS-treated mice (Fig. 2b, Supplementary Figs. 4 b and Fig. 15 and Supplementary Table 1). Including human albumin NPs (Fig. 1c), five of the formulations had selectivity for inflamed lungs (Supplementary Table 5). Lysozyme nanoparticles were not selective for inflamed lungs, but accumulated in both naive and inflamed lungs in high concentrations.

Nanoparticles based on electrostatic protein interactions. Electron microscopy studies and functional assays have recently characterized nanoparticles based on interactions between charged proteins and oppositely charged polymers or gold nanoclusters ${ }^{48-50}$. We traced nanoparticles comprising poly(glutamate)-tagged green fluorescent protein (E-GFP) combined with arginine-gold nanoparticles (diameter, $89.0 \pm 1.6 \mathrm{~nm}$; PDI, $0.14 \pm 0.04$; zeta potential, $-6.4 \pm 0.5 \mathrm{mV}$ ) or with poly(oxanorborneneimide) (PONI) with guanidino and tyrosyl groups (diameter, $158.9 \pm 6.2 \mathrm{~nm}$; PDI, $0.17 \pm 0.03$; zeta potential, $18.3 \pm 0.5 \mathrm{mV}$ ) (Supplementary Fig. $4 \mathrm{c}$ and Supplementary Table 1). For PONI/E-GFP nanoparticles, PONI was labelled with ${ }^{131}$ I and E-GFP was labelled with ${ }^{125}$ I to trace both components of the nanoparticles. PONI/E-GFP and argininegold/E-GFP nanoparticles were both selective for i.v.-LPS-affected lungs (Fig. 2c and Supplementary Fig. 16). PONI and E-GFP components of PONI/E-GFP nanoparticles accumulated in inflamed lungs at similar concentrations.

Nanoparticles based on symmetric protein arrangement. Adenoassociated virus, adenovirus and horse spleen ferritin are nanoparticles based on arrangement of protein in symmetric structures (sizes in Supplementary Fig. 4c, zeta potentials in Supplementary Table $1)^{51-56}$. Adeno-associated virus serotype 8 , human adenovirus and horse spleen ferritin had no selectivity for i.v.-LPS-affected lungs (Fig. 2d, Supplementary Fig. 17 and Supplementary Table 6).

Non-protein nanoparticles. PEGylated liposomes $(103.6 \pm 8.7 \mathrm{~nm}$; PDI, $0.09 \pm 0.01$; zeta potential, $-2.2 \pm 0.2 \mathrm{mV}$ ) were traced with ${ }^{111}$ In-DOTA-lipids and carboxylate polystyrene nanoparticles were conjugated to tracer ${ }^{125} \mathrm{I}$-immunoglobulin $\mathrm{G}$ (IgG) $(230.5 \pm 2.8$ $\mathrm{nm}$; PDI, $0.14 \pm 0.0$; zeta potential, $-4.0 \pm 0.8 \mathrm{mV}$; Supplementary
Fig. 2c,d and Supplementary Table 1). As example nanoparticles with few or no proteins, these two nanoparticles did not home to i.v.-LPS-affected lungs (Fig. 2e and Supplementary Fig. 18).

Free protein controls. As compared to nanoparticles based on bovine albumin, hen lysozyme and human transferrin, our results indicate that albumin, lysozyme and transferrin themselves do not home to or have selectivity for i.v.-LPS-affected lungs (Supplementary Fig. 19 and Supplementary Table 7).

Protein-conjugated liposomes. Beyond data with PEGylated liposomes above, we traced protein-conjugated liposomes in naive and i.v.-LPS-treated mice. Liposomes were functionalized with rat IgG conjugated via $N$-succinimidyl $S$-acetylthioglycolate-maleimide (SATA-maleimide) chemistry (178.8 $\pm 6.9 \mathrm{~nm}$; PDI, $0.23 \pm 0.03$; zeta potential, $-2.1 \pm 0.5 \mathrm{mV})$ or via click chemistry methods $(128.3 \pm$ $4.3 \mathrm{~nm}$; PDI, $0.17 \pm 0.03$; zeta potential, $-4.1 \pm 0.2 \mathrm{mV}$ ), in which IgG was conjugated to dibenzocyclooctyne (DBCO) and the modified IgG was conjugated to azide-liposomes (Fig. 3a, Supplementary Fig. 4d and Supplementary Table 1$)^{57}$. Compared to bare and SATA-IgG liposomes, DBCO-IgG liposomes had enhanced tropism for i.v.-LPS-affected lungs (Fig. 3b, Supplementary Fig. 20 and Supplementary Table 8). i.t.-LPS injury also enhanced lung uptake of DBCO-IgG liposomes (Supplementary Fig. 21). Flow cytometry with fluorescent DBCO-IgG liposomes confirmed liposome tropism for neutrophils in inflamed lungs (Fig. 3c,d and Supplementary Fig. 22). Approximately $90 \%$ of liposome signal in inflamed lungs was in neutrophils and $>98 \%$ was in leukocytes.

We confirmed that DBCO modification of IgG confers neutrophil tropism on IgG liposomes by titrating the DBCO:IgG ratio (Supplementary Fig. 4d for liposome sizes, Supplementary Fig. 23, Supplementary Table 1 for liposome zeta potentials). The results in Fig. 3b used 20 DBCO per IgG. Reducing DBCO:IgG reduced DBCO-IgG liposome uptake in i.v.-LPS-affected lungs (Fig. 3e and Supplementary Table 9). DBCO-IgG itself did not accumulate in the lungs (Supplementary Fig. 24), showing that incorporation of the modified protein in nanoparticle structure was necessary for inflamed lung tropism. CD spectroscopy indicated DBCO did not change the IgG secondary structure (Supplementary Fig. 25).

In the above data, NAPs based on hydrophobic interactions, crosslinking and charge interactions all exhibited selectivity for inflamed lungs (Fig. 2a-c), with additional data indicating that this selectivity is based on tropism for marginated neutrophils (Fig. 1). Adding hydrophobic DBCO to protein on liposomes led to liposome uptake in neutrophils in inflamed lungs (Fig. 3), indicating that hydrophobic interactions between proteins on liposome surfaces also predict tropism for marginated neutrophils. Nanoparticles

Fig. 2 | Screen of diverse NP biodistributions in naive and i.v.-LPS-affected lungs. a-c, NAPs accumulate in acutely inflamed lungs. a, Biodistributions of variant NGs indicating uptake of $75 \mathrm{~nm} \mathrm{NGs}\left(n=4\right.$ i.v.-LPS animals, $n=4$ naive animals, red box: $\left.P<1 \times 10^{-10}\right)$ and $200 \mathrm{~nm}$ NGs $(n=5$ i.v.-LPS, $n=5$ naive, red box: $p<1 \times 10^{-10}$ ) in LPS-injured lungs, but not naive lungs. Data for $130 \mathrm{~nm}$ NGs are identical to that presented in Fig. $1 \mathrm{~b}$. $\mathbf{b}$, Biodistributions of variant crosslinked albumin NPs indicating uptake of albumin nanorods ( $n=3$ i.v.-LPS animals, $n=3$ naive animals; red box, $P<1 \times 10^{-10}$ ) and bovine albumin NPs ( $n=3$ i.v.-LPS animals, $n=3$ naive animals; red box, $P<1 \times 10^{-10}$ ) in LPS-injured, but not naive lungs. Data for human albumin nanoparticles are identical to that presented in Fig. 1C. c, Biodistributions of charge-agglutinated protein NPs, indicating uptake of particles comprised of E-GFP and guanidine-tagged PONI or particles comprised of E-GFP and guanidine-tagged gold nanoparticles in LPS-injured (PONI: $n=5$ animals; Au: $n=3$ animals), but not naive (PONI: $n=4$ animals; Au: $n=3$ animals) lungs. PONI/E-GFP data reflect tracing of both ${ }^{131}$ I-labelled PONI and ${ }^{125}$ I-labelled E-GFP. For PONI tracer data: red box, $P<1 \times 10^{-10}$. For E-GFP tracer data: red box, $P=0.0003$. For Au/E-GFP data: red box, $P=1.6 \times 10^{-9}$. d, NPs based on symmetric supramolecular arrangement of protein do not have tropism for inflamed lungs (schematics created with BioRender.com). Biodistributions of adenovirus ( $n=5$ i.v.-LPS animals, $n=5$ naive animals; blue box, $P=0.88$ ), adeno-associated virus ( $n=3$ i.v.-LPS animals, $n=3$ naive animals; blue box, $P=0.56)$ and ferritin nanocages ( $n=5$ i.v.-LPS animals, $n=5$ naive animals; blue box, $P=0.35$ ) indicating no selectivity for LPS-injured versus naive lungs. e, Biodistributions of bare liposomes (schematic created with BioRender.com, $n=4$ i.v.-LPS animals, $n=4$ naive animals) indicating no selectivity for LPS-injured versus naive lungs (blue box, $P=0.31$ ). Biodistributions of IgG-coated polystyrene NPs indicating low levels of uptake in both naive ( $n=4$ animals) and LPS-injured ( $n=4$ animals) lungs (blue box, $P=0.0004$ ). Statistical significance in all panels is derived from two-way ANOVA with Sidak's multiple comparisons test. All error bars indicate mean \pm s.e. $m$. 
based on highly symmetric protein arrangements had no tropism for inflamed lungs (Fig. 2d). NAP selectivity for inflamed lungs did not linearly correlate with size or zeta potential (Supplementary
Fig. 26), accommodated both spheres and rods, and was observed with eight different types of protein. Agglutinated protein was unique as a structural motif common to all nanoparticles with high

NAPs: enhanced uptake in inflamed lungs

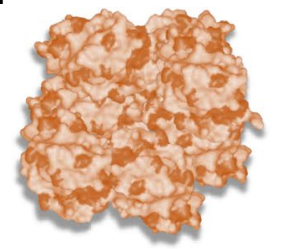

Hydrophobic protein interactions

(for example, heat gelation)
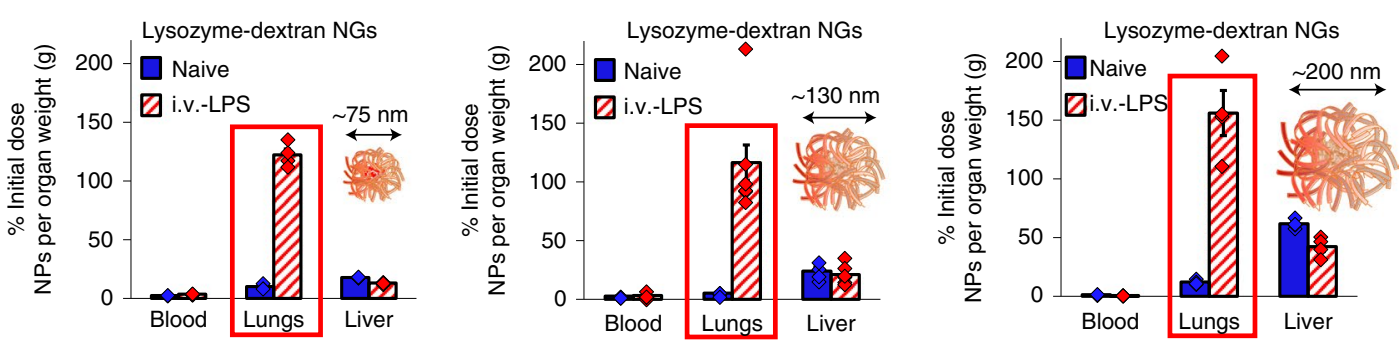

b

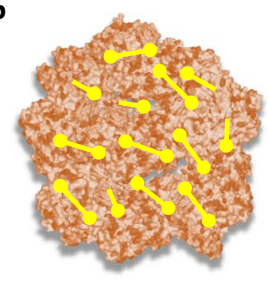

Crosslinked protein
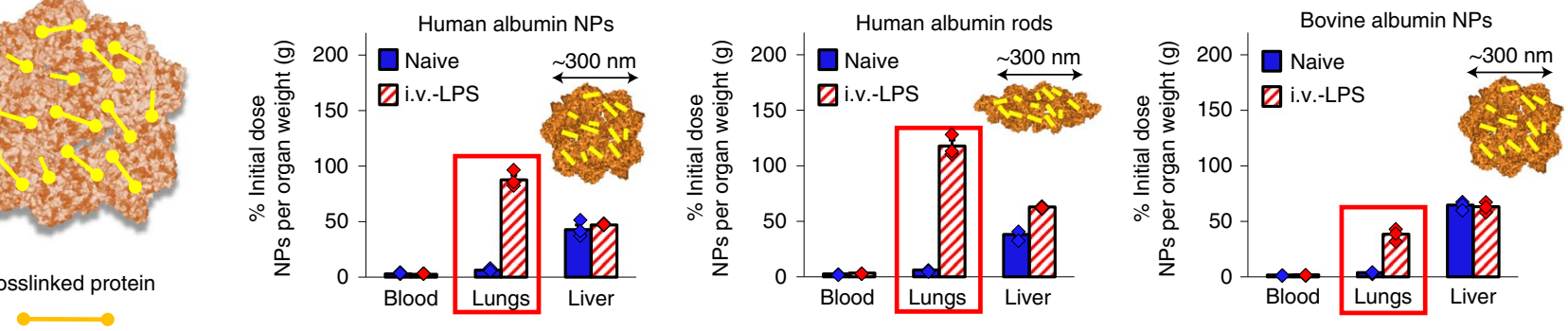
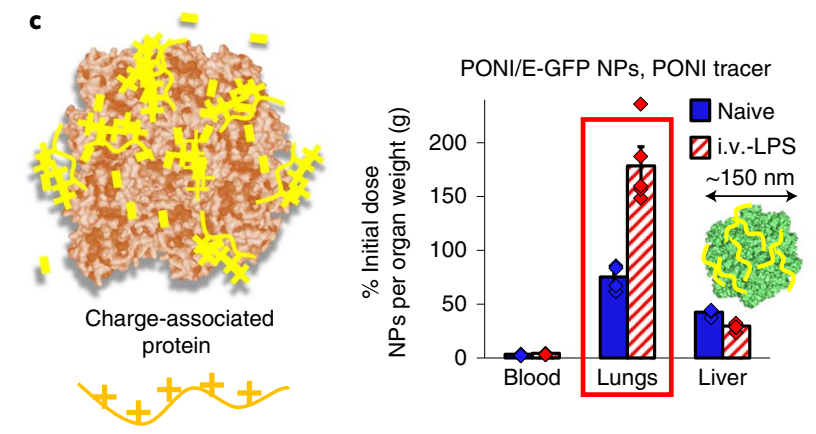

PONI/E-GFP NPs, E-GFP tracer

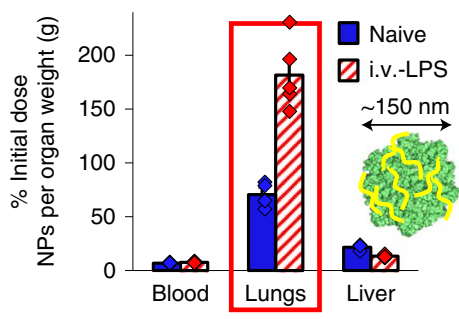

Au/E-GFP NPs, E-GFP tracer

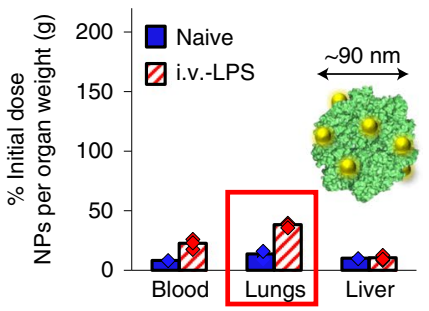

No selective uptake in inflamed lungs

d

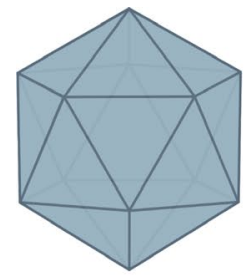

Symmetric/regular protein arrangement (for example, viral capsids)
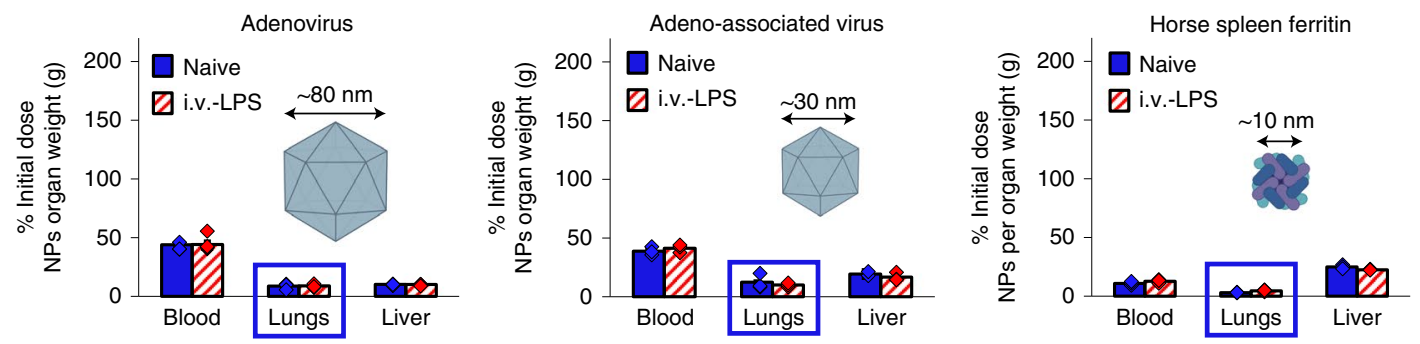

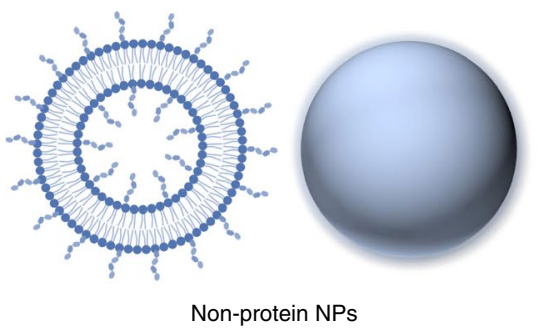

(for example, liposomes, polymeric NPs)
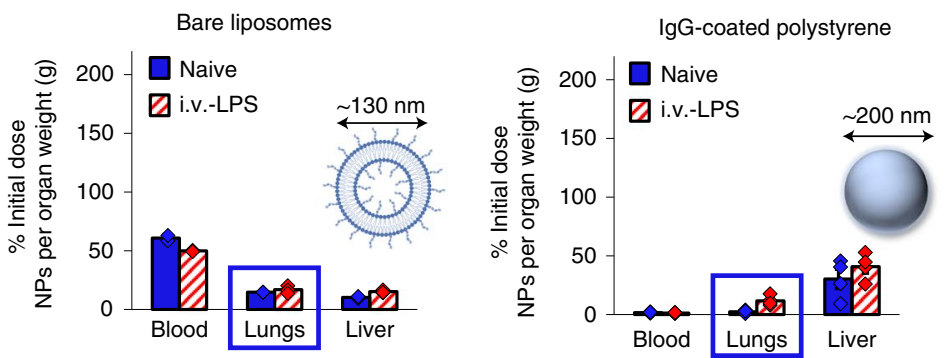

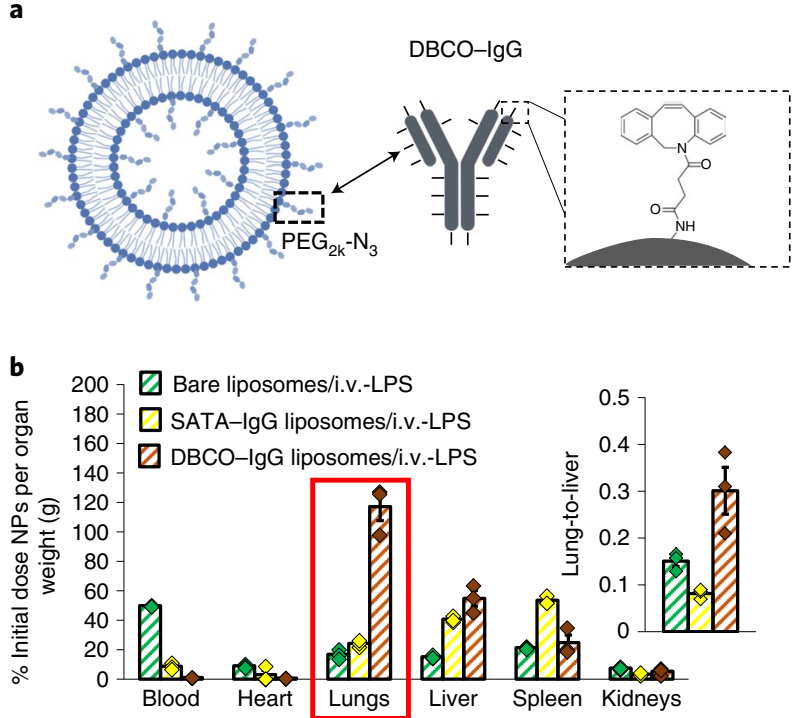

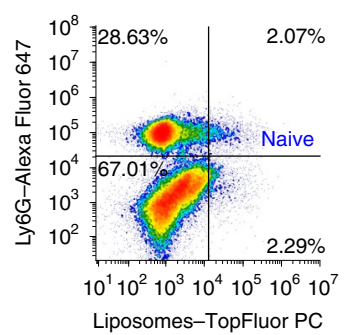

d

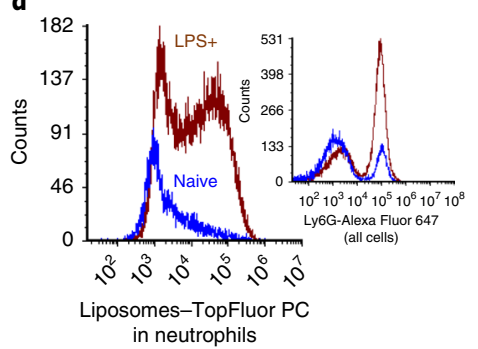

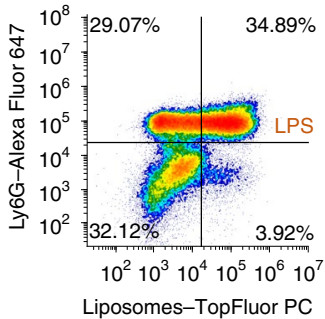

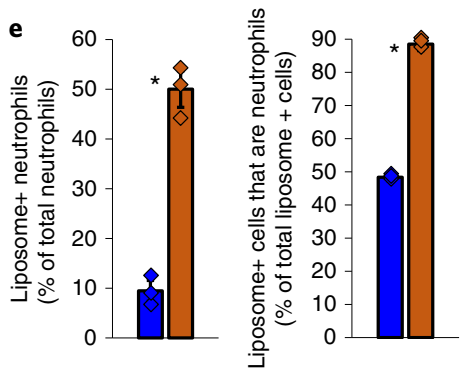

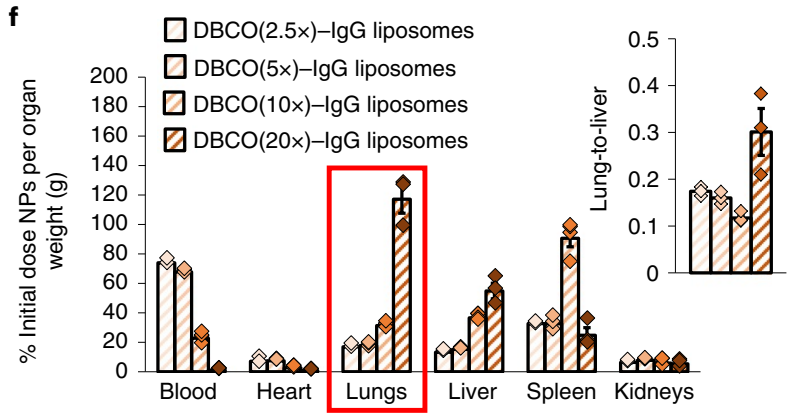

Fig. 3 | Engineering of liposome surface chemistry to confer NAP-like behaviour in LPS-inflamed lungs. a, Schematic of antibody-coated liposomes prepared via copper-free click reaction of azide-functionalized liposomes with DBCO-functionalized IgG (liposome schematic created with BioRender. com). $\mathbf{b}$, Biodistributions in i.v.-LPS-injured mice for bare liposomes ( $n=3$ animals), liposomes conjugated to $\lg$ via SATA-maleimide chemistry $(n=3$ animals) and liposomes conjugated to IgG via DBCO-azide chemistry ( $n=3$ animals) (red box, $P<1 \times 10^{-10}$ for DBCO-IgG liposomes versus bare liposomes and DBCO-lgG liposomes versus SATA-IgG liposomes). c, Mouse lung flow cytometry data indicating Ly6G anti-neutrophil staining density versus levels of DBCO-IgG liposome uptake as indicated by the green fluorescent TopFluor PC lipid signal. d, Flow cytometry data verifying increased DBCO-lgG liposome uptake in and selectivity for neutrophils following LPS insult. Inset: verification of increased concentration of neutrophils in the lungs following LPS. e, Fraction of neutrophils positive for DBCO-IgG liposomes in naive ( $n=3$ animals) or i.v.-LPS-injured ( $n=3$ animals) lungs ( ${ }^{\star} P=0.0003$ ) and fraction of DBCO-lgG liposome-positive cells that are neutrophils $\left({ }^{\star} P=1.7 \times 10^{-6}\right)$. $\mathbf{f}$, Biodistributions in i.v.-LPS-injured mice for azide-functionalized liposomes conjugated to IgG loaded with 2.5 ( $n=3$ animals), 5 ( $n=3$ animals), 10 ( $n=4$ animals) and 20 DBCO molecules per lgG ( $n=3$ animals; red box, $P<1 \times 10^{-10}$ for DBCO(20x)-IgG liposomes compared to each of the other DBCO density groups). Insets in $\mathbf{b}$ and $\mathbf{f}$ : ratio of NP uptake in the lungs to NP uptake in the liver. Statistical significance in $\mathbf{b}$ and $\mathbf{f}$ is derived from two-way ANOVA with Tukey's multiple-comparisons test. Statistical significance in $\mathbf{e}$ is derived from paired two-tailed $t$ tests. All error bars indicate mean \pm s.e.m.

selectivity for inflamed lungs. Principal component and linear discriminant analyses of our compiled biodistributions confirmed that (1) NAPs stood out from the other tested nanoparticles in their tropism for inflamed lungs; and (2) DBCO-IgG liposomes aligned with other NAPs (Supplementary Figs. 27 and 28).

\section{Complement opsonization as a mechanism in NAP tropism for neutrophils}

We conducted in vitro and in vivo studies isolating biological mechanisms by which neutrophils recognize NAPs. Exposure of NGs to serum before in vitro incubation with neutrophils led to a $>30$-fold increase in NG uptake (Fig. 4a and Supplementary Fig. 29a,b). We hypothesized that serum opsonins are a determinant in NG interactions with neutrophils. Mass spectrometry quantified the abundance of different proteins adsorbed on NGs after incubation in serum, identifying large quantities of complement proteins $\mathrm{C} 3$ and C5 (Fig. 4b and Supplementary Fig. 30a). C3 and C5 were significantly more abundant than complement $\mathrm{C} 2$ and $\mathrm{C} 4$ (C3 versus $\mathrm{C} 2$ :
$P<1 \times 10^{-10}$, C3 versus C4: $P<1 \times 10^{-10}$, C5 versus C2: $P<1 \times 10^{-10}$, C5 versus $C 4: P=0.011$ ), signifying predominance of alternative pathway complement activation ${ }^{58}$.

Serum was heat treated to inactivate complement ${ }^{59}$. Heat treatment eliminated the effect of serum on NG uptake in neutrophils (Fig. 4c and Supplementary Fig. 29a, b). Cobra venom factor (CVF) treatment to deplete serum complement by $\mathrm{C} 3$ activation $^{60}$ also eliminated serum effects on NG-neutrophil interactions (Fig. 4c and Supplementary Fig. 29a,b). Serum from a mouse treated with CVF yielded identical results (Supplementary Fig. 29a,b). In vitro, LPS stimulation of neutrophils did not modify NG uptake (Fig. $4 \mathrm{~d}$ and Supplementary Fig. 29c,d). In vitro, complement interactions with NAPs, rather than LPS stimulation of neutrophils, determined NAP uptake in neutrophils.

We treated mice with intraperitoneal CVF to deplete complement in vivo before NAP administration. CVF treatment reduced NG tropism for i.v.-LPS-inflamed lungs by $>50 \%$, with a $>5$-fold reduction in the lungs:blood ratio (Fig. 4e and Supplementary Fig. 31). 
a

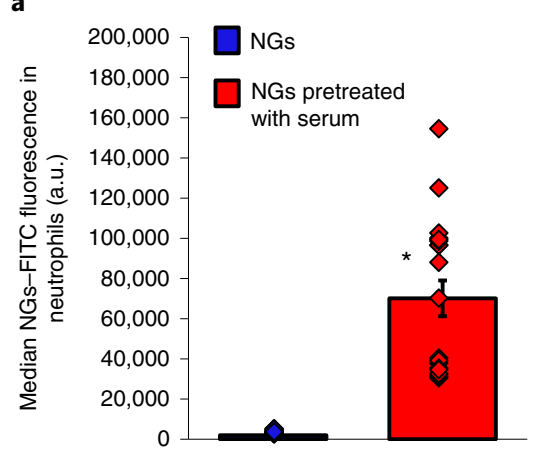

b

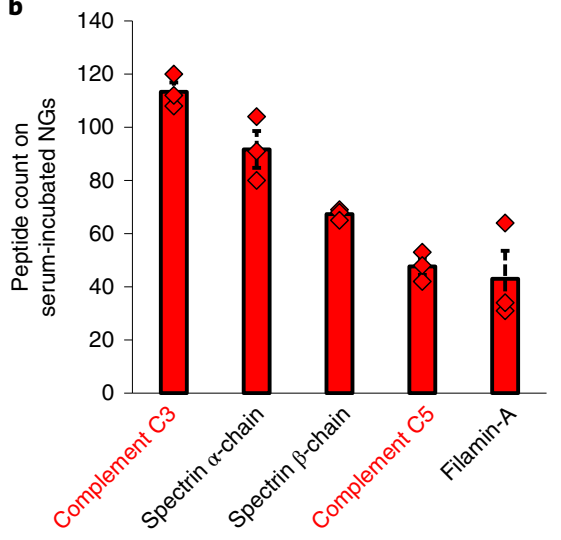

c

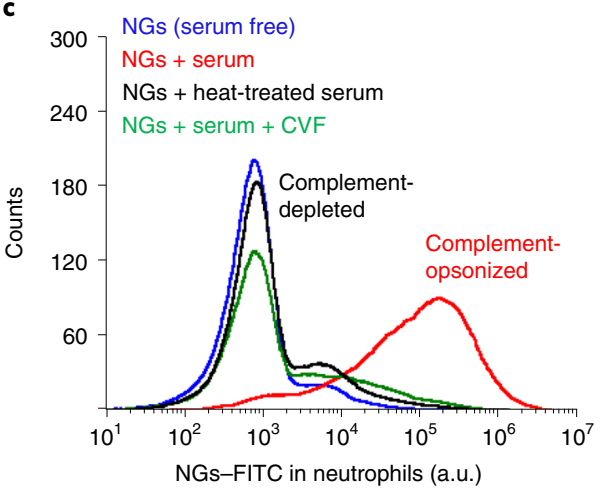

d

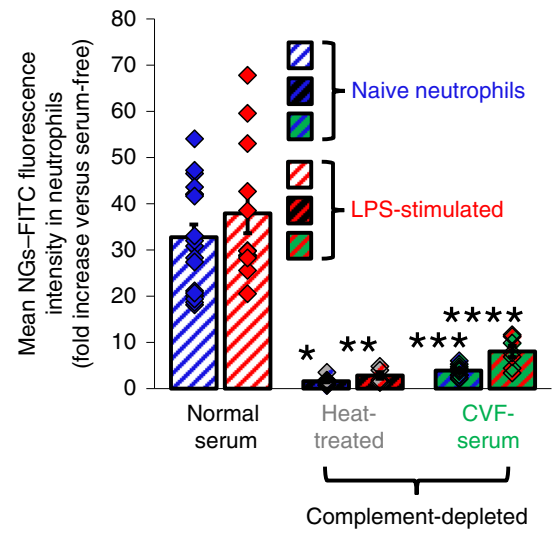

e

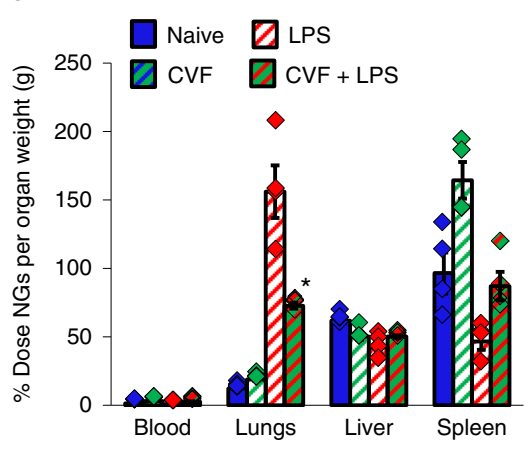

Fig. 4 | Complement opsonization of NAPs is necessary for NAP uptake in neutrophils. a, Flow cytometry data indicating neutrophils take up lysozymedextran NGs after NG incubation in mouse serum ( $n=18$ biological replicates) but not after NG incubation in buffer ( $n=18$ biological replicates; $\left.{ }^{\star} P=6.9 \times 10^{-9}\right) . \mathbf{b}$, Mass spectrometry characterization of proteins adsorbed on NGs after incubation with mouse serum as in a. Plotted data indicate the concentration of detected peptides associated with the five most abundant proteins on serum-incubated NGs ( $n=3$ serum/NG preparations). Complement proteins are highlighted in red text. c,d, Flow cytometric assessment of NG uptake in mouse neutrophils after NG incubation with buffer, mouse serum, heat-treated mouse serum and mouse serum treated with CVF: example histograms of NG fluorescence in neutrophils for different serum conditions (c); data reflecting NG mean fluorescence in neutrophils for different serum conditions (d). In d, bars with blue stripes indicate naive neutrophils ( $n=18$ biological replicates for naive serum, $n=10$ for heat-treated serum, $n=11$ for CVF-treated serum) and bars with red stripes indicate LPS-stimulated neutrophils ( $n=12$ biological replicates for naive serum, $n=5$ for heat-treated serum, $n=7$ for CVF-treated serum). For comparison to normal serum/naive, ${ }^{\star} P<1 \times 10^{-10}$ and ${ }^{\star \star} P<1 \times 10^{-10}$. For comparison to normal serum/LPS, ${ }^{\star \star \star} P=7.3 \times 10^{-10}$ and ${ }^{\star \star \star \star} P=3.7 \times 10^{-9}$. e, Biodistributions of NGs in naive mice ( $n=4$ animals), mice treated with CVF ( $n=4$ animals), mice treated with i.v. LPS ( $n=4$ animals) and mice treated with i.v. LPS and CVF ( $n=4$ animals). Naïve and i.v.-LPS data are identical to that presented in Supplementary Fig. 13, upper right panel. For comparison between LPS and CVF + LPS groups, ${ }^{\star} P=1.6 \times 10^{-10}$. f, Mass spectrometry characterization of complement opsonization of NGs ( $n=3$ serum/NG preparations) and human adenovirus ( $n=3$ serum/adenovirus preparations). Peptide count data as in $\mathbf{b}$ is normalized to peptide counts on NGs incubated with complement-depleted CVF-treated serum. Relative complement quantities below zero indicate complement opsonization at lower levels than on NGs after treatment with complement-depleted serum. Statistical significance in a is derived from paired two-tailed $t$ tests. Statistical significance in d is derived from one-way ANOVA with Tukey's multiple-comparisons test. Statistical significance in e is derived from two-way ANOVA with Tukey's multiple-comparisons test. All error bars indicate mean \pm s.e.m.

We also performed mass spectrometry analysis of serum proteins on adenovirus capsids, a protein nanoparticle with no tropism for neutrophils in inflamed lungs. All tested complement proteins were reduced on adenovirus versus NGs, with $\mathrm{C} 5$ and factor B absent on adenovirus (Fig. $4 \mathrm{f}$ and Supplementary Fig. 30a-c). CVF treatment of serum reduced the quantities of $\mathrm{C} 3$ and factor $\mathrm{B}$ on NGs, and the levels of these proteins on adenovirus capsid with naive serum were less than those on NGs with complement-depleted serum (Supplementary Fig. 30c).

\section{Imaging lung inflammation with NAPs}

Computerized tomography (CT) imaging can diagnose ALI by detecting pulmonary oedema, but cannot distinguish ALI from cardiogenic pulmonary oedema $(\mathrm{CPO})^{61}$. $\mathrm{CPO}$ was induced in mice via propranolol infusion ${ }^{62}$. CT imaging confirmed pulmonary oedema after propranolol infusion (Fig. 5a,b, Supplementary Fig. 32 and Supplementary Movies 2 and 3). NGs homed to i.v.-LPS-affected lungs, but not CPO-affected lungs (Fig. 5c). We tested NGs as single-photon emission computerized tomography (SPECT)-CT contrast agents for ALI by imaging ${ }^{111}$ In-labelled NGs (Supplementary Fig. 33) in naive and i.v.-LPS-affected lungs. ${ }^{111}$ In SPECT signal was detectable in LPS-affected lungs, but at background level in naive lungs (Fig. 5d and Supplementary Movies 4-7). Previous studies have noted the potential for diagnostic imaging of lung inflammation based on neutrophils, including clinical data with autologous neutrophils in ALI and chronic obstructive pulmonary disease ${ }^{12,63}$. Our studies used NAP tropism for neutrophils to non-invasively image lung inflammation. 

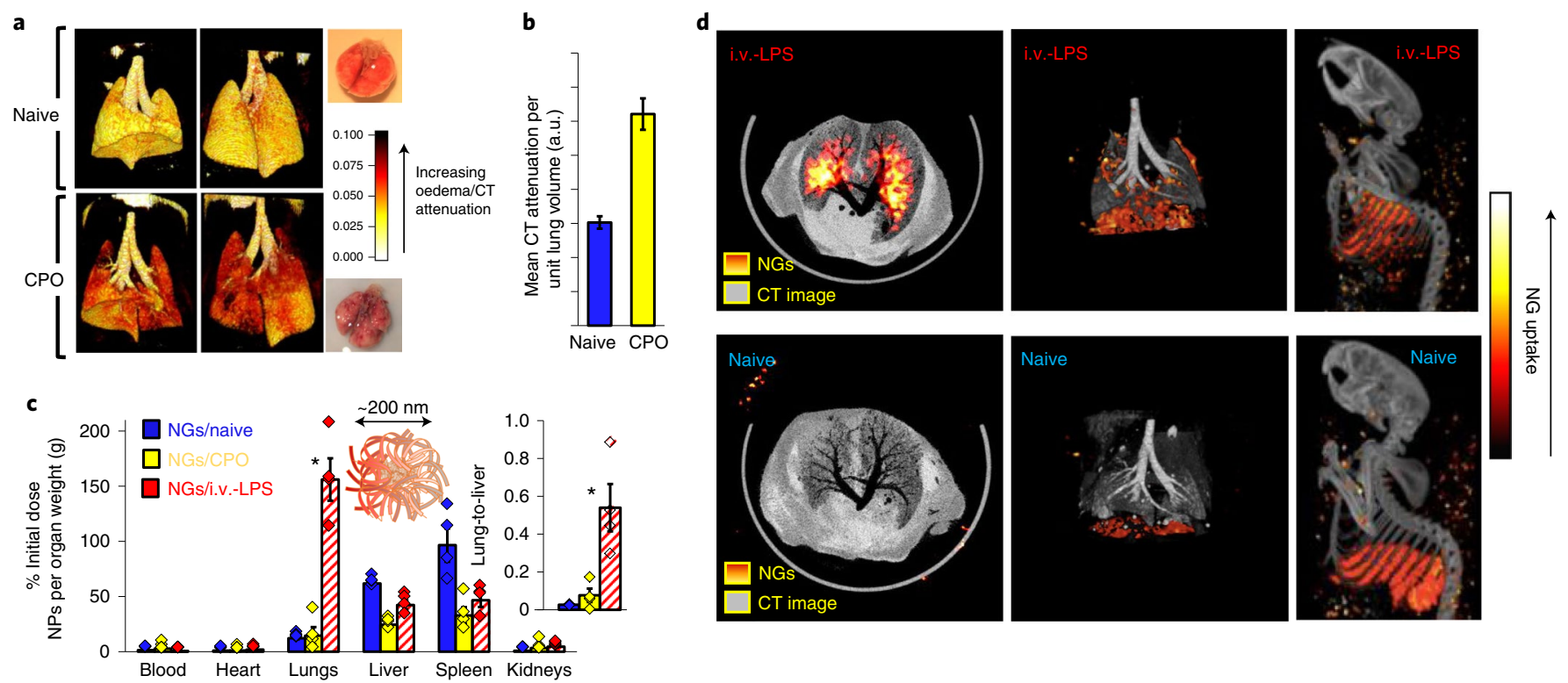

Fig. 5 | Specificity of NAPs for LPS-inflamed lungs versus oedematous lungs and SPECT imaging of NAPs in LPS-inflamed lungs. a, Three-dimensional reconstructions of chest CT data for naive mouse lungs and lungs with CPO. White/yellow indicates lower attenuation, corresponding to airspace in healthy lungs. Red/dark background indicates higher attenuation, corresponding to fluid in the lungs. $\mathbf{b}$, Quantification of CT attenuation in naive (blue) and oedematous (yellow) lungs, averaged across axial slices (individual slice values in Supplementary Fig. 32). c, Biodistributions of 200 nm lysozyme-dextran NGs in naive mice, mice treated with i.v.-LPS and mice subject to CPO ( $n=4$ animals). Naïve and i.v.-LPS data are identical to that presented in Supplementary Fig. 13, upper right panel. Inset: ratio of NP uptake in the lungs to NP uptake in the liver. For comparison of CPO and i.v.-LPS values, ${ }^{\star} P<1 \times 10^{-10}$ for main panel and $P=0.005$ for inset. d, Co-registered CT (greyscale) and SPECT (red/yellow) images indicating ${ }^{111}$ In-labelled lysozyme-dextran NG uptake in a naive and an i.v.-LPS-affected mouse. White/yellow indicates more nanogel uptake. Red/dark background indicates less lysozyme-dextran NG uptake. Statistical significance in c is derived from two-way ANOVA with Tukey's multiple-comparisons test. All error bars indicate mean \pm s.e.m

\section{NAP accumulation in inflamed human lungs ex vivo}

We performed experiments to test NAP tropism for inflamed human lungs. NGs were added to single-cell suspensions prepared from human lungs. NGs accumulated in leukocytes in the suspensions in a dose-dependent manner (Supplementary Fig. 34a,b). Fluorescent or ${ }^{125}$ I-labelled NGs were infused via arterial catheter into ex vivo human lungs excluded from transplant due to lung damage ${ }^{64}$. Tissue dye indicated areas of the lungs perfused by NG suspensions (Supplementary Fig. 34c). For fluorescent NG experiments, high- and low-perfusion regions were selected for histology. NGs were detectable only in well-perfused tissue (Supplementary Fig. 34d). In experiments with ${ }^{125} \mathrm{I}-\mathrm{NGs},{ }^{131} \mathrm{I}$-ferritin was concurrently infused as a control particle without tropism for injured mouse lungs. NGs retained in human lungs at $>5$-fold higher concentration than ferritin (Supplementary Fig. 34e). NGs were concentrated in highly perfused lung regions, while ferritin was uniformly distributed (Supplementary Fig. 35). Our data indicate that NAP tropism for neutrophils in inflamed mouse lungs may be recapitulated in human lungs.

\section{Effects of NAPs in acute lung inflammation}

Mice were treated with nebulized LPS as a high-throughput model for severe acute respiratory distress syndrome (ARDS) ${ }^{65}$. Histology showed that nebulized LPS caused haemorrhage and airway infiltration by neutrophils $24 \mathrm{~h}$ after insult (Supplementary Fig. 36). In bronchoalveolar lavage fluid (BALF), nebulized LPS elevated neutrophil/leukocyte concentrations 50-fold and protein concentration 3-fold (Fig. 6a,b and Supplementary Fig. 37), indicating vascular disruption and oedema.

DBCO-IgG liposomes, NGs and bare liposomes were administered (dose, $30 \mathrm{mg} \mathrm{kg}^{-1}$ ) $2 \mathrm{~h}$ after nebulized LPS. BALF leukocytes and protein were reduced by $>50 \%$ by DBCO-IgG liposomes, but were unaffected by bare liposomes and NGs (Fig. 6a,b and Supplementary Fig. 37). DBCO-IgG liposome effects on BALF leukocytes and protein were dose dependent, with $\mathrm{IC}_{50} \mathrm{~s}$ of 5.7 and $1.5 \mathrm{mg} \mathrm{kg}^{-1}$, respectively (Fig. 6c,d and Supplementary Fig. 38). CXCL2, a chemoattractant in neutrophil diapedesis ${ }^{66}$, was elevated in BALF and liver by nebulized LPS. BALF and liver CXCL2 were reduced by DBCO-IgG liposomes (Fig. 6e and Supplementary Fig. 39). Cytokine IL-6 is elevated in plasma in severe ARDS ${ }^{67}$. In our model, DBCO-IgG liposomes suppressed plasma IL-6 in a dose-dependent manner (Supplementary Fig. 40).

DBCO-IgG liposomes suppressed neutrophil accumulation in BALF in a manner consistent with suppression of BALF leukocytes (Fig. 6f and Supplementary Fig. 41). Quantifying intravascular neutrophils via radiotracer Ly6G antibody, we found DBCO-IgG liposomes reduced pulmonary marginated neutrophils, increased circulating neutrophils, and transiently increased spleen neutrophils, relative to untreated values (Fig. $6 \mathrm{~g}$ and Supplementary Fig. 42). Complete blood count (CBC) confirmed DBCO-IgG liposome effects on circulating neutrophils (Fig. $6 \mathrm{~h}$ and Supplementary Fig. 43). CBC also indicated that DBCO-IgG liposomes mitigate LPS suppression of lymphocytes and platelets and have insignificant effects on red blood cells (Supplementary Figs. 43 and 44).

These findings indicate that DBCO-IgG liposomes cause neutrophils to leave the lungs, getting sequestered in the spleen or returning to circulation. Accordingly, we observe lower neutrophil extravasation into alveoli and less oedema after DBCO-IgG liposome treatment (Fig. 6i). DBCO-IgG liposomes had no significant effects on body weight (Supplementary Fig. 45), but changes to signalling molecules CXCL2 and IL- 6 and effects on platelets and lymphocytes indicate systemic effects for these NAPs. 

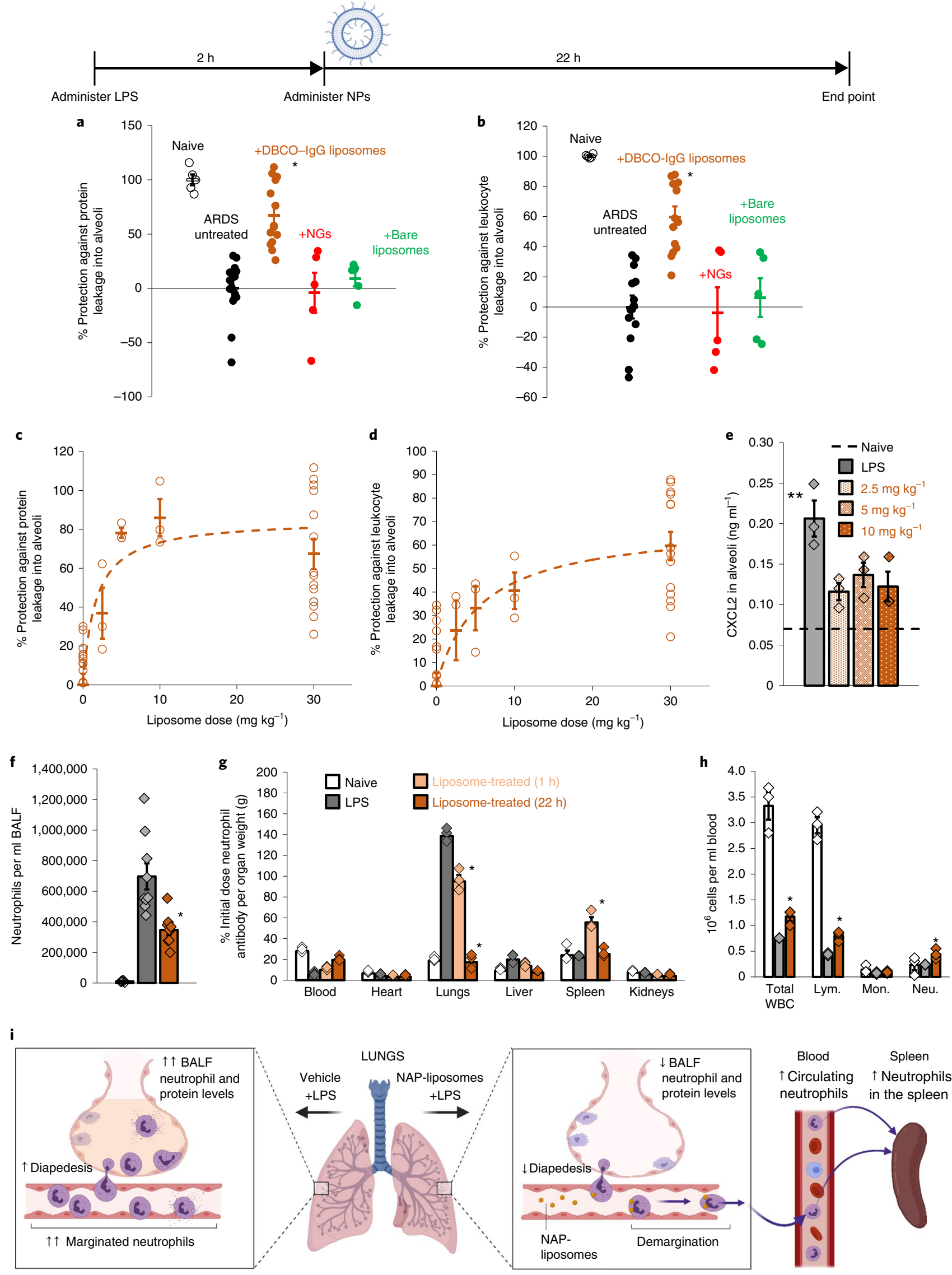
Fig. 6 | Effects of NAPs in model ARDS. Timeline: nanoparticles or vehicle were administered as an i.v. bolus $2 \mathrm{~h}$ after nebulized LPS administration (liposome schematic created with BioRender.com). a,b, BALF was harvested $22 \mathrm{~h}$ after nanoparticle ( $\left.30 \mathrm{mg} \mathrm{kg}{ }^{-1}\right)$ or vehicle administration. $\mathbf{a}$, Protein concentration in BALF, reflecting quantity of oedema in naive mice ( $n=5$ animals), sham-treated mice with model ARDS ( $n=15$ animals) and mice with model ARDS treated with DBCO-IgG liposomes ( $n=14$ animals), NGs $\left(n=5\right.$ animals) or bare PEGylated liposomes $\left(n=5\right.$ animals). ${ }^{\star} P=6.6 \times 10^{-7}$, 0.0001 and 0.002 for comparison of DBCO-IgG liposome treatment with sham treatment, NG treatment and bare liposome treatment, respectively. b, Concentration of leukocytes in BALF for same groups as in $\mathbf{a}$. ${ }^{\star} P=1.1 \times 10^{-6}, 0.0001$ and 0.002 for comparison of DBCO-IgG liposome treatment with sham treatment, NG treatment and bare liposome treatment, respectively. Quantities in $\mathbf{a}$ and $\mathbf{b}$ are represented as degree of protection against infiltration into alveoli, extrapolated from levels in naive mice (100\% protection) and untreated mice with model ARDS (0\% protection). c,d, Dose-response for oedema (c) and leukocyte infiltration (d) in alveoli of ARDS mice treated with DBCO-IgG liposomes. Data were obtained as in $\mathbf{a}$ and $\mathbf{b}$, but with different liposome doses ( $n=3$ animals for 2.5, 5 and $10 \mathrm{mg} \mathrm{kg}^{-1}$ liposome doses). e, Chemokine CXCL2 levels in alveoli of LPS-injured mice with and without DBCO-IgG liposome treatment ( $n=3$ animals for all groups). Dashed line indicates CXCL2 levels in alveoli of naive mice. ${ }^{\star \star} P=0.024,0.079$ and 0.034 for comparison of sham treatment with $2.5,5$ and $10 \mathrm{mg} \mathrm{kg}^{-1}$ DBCO-lgG liposome treatment, respectively. $\mathbf{f}$, Concentration of neutrophils in BALF of naive mice ( $n=5$ animals), mice with model ARDS ( $n=9$ animals) and mice with model ARDS dosed with $30 \mathrm{mg} \mathrm{kg}^{-1} \mathrm{DBCO}-\mathrm{lgG}$ liposomes ( $n=9$ animals). For comparison of DBCO-lgG liposome treatment to sham treatment, ${ }^{\star} P=0.009$. $\mathbf{g}$, Biodistributions of anti-Ly6G antibody in naive mice ( $n=3$ animals), LPS-injured mice ( $n=3$ animals) and mice treated with $10 \mathrm{mg} \mathrm{kg}^{-1}$ DBCO-lgG liposomes, with organs sampled at $1 \mathrm{~h}$ after treatment ( $n=3$ animals) or $22 \mathrm{~h}$ after treatment ( $n=3$ animals). Naive and untreated LPS-affected data are identical to data in Supplementary Fig. $1 a$. ${ }^{\star} P<1 \times 10^{-10}$ for all comparisons of anti-Ly6G uptake in lungs or spleen of liposome-treated mice versus sham-treated mice. $\mathbf{h}$, Complete blood count analysis of circulating leukocyte concentrations in naive mice ( $n=3$ animals), LPS-injured mice ( $n=3$ animals) and mice treated with 10 mg kg-1 DBCO-lgG liposomes, with blood sampled $22 \mathrm{~h}$ after treatment ( $n=3$ animals). ${ }^{\star} P=0.019,0.025$ and 0.047 for comparison of DBCO-IgG liposome-treated to sham-treated values for total white blood cell (WBC), lymphocyte (Lym.) and neutrophil (Neu.) counts, respectively. $\mathbf{i}$, Schematic for the fate of neutrophils in mice with model ARDS, with and without DBCO-IgG liposome treatment, based on data in $\mathbf{f - h}$ (created with BioRender.com). Statistical significance in $\mathbf{a}, \mathbf{b}$, e and $\mathbf{f}$ is derived from one-way ANOVA with Tukey's multiple-comparisons test. Statistical significance in $\mathbf{g}$ and $\mathbf{h}$ is derived from two-way ANOVA with Tukey's multiple-comparisons test. All error bars indicate mean \pm s.e.m.

\section{Conclusions}

This study identifies nanoparticle properties leading to tropism for neutrophils in inflamed lungs. These neutrophils take up NAPs, but not nanoparticles whose surface proteins are arranged with regular and symmetric spacing (for example, viral capsids and protein nanocages $\left.^{51,53-56}\right)$. 'Agglutination' is defined here by the three types of protein-protein interactions enumerated in Fig. 2, which are designed without specific supramolecular arrangement. Electron microscopy data confirm there is no symmetry or regularity in protein-protein spacing in NAPs ${ }^{35,37,43,46,47,49,50}$. Thus, the structures of nanoparticles tested in our studies are differentiated by arrangement of protein at the supramolecular scale: nanoparticles with or without regular spacing and symmetry in protein arrangement. Differences in nanoparticle tropism for neutrophils in inflamed lungs aligned with differences in supramolecular-scale protein arrangement, but not differences in size, shape or zeta potential (Supplementary Figs. 26-28).

Supporting our conclusions, we re-engineered liposomes to behave like NAPs. We hypothesized that addition of the hydrophobic molecule DBCO to IgG on liposomes would recapitulate the protein 'agglutination' seen in NAPs based on hydrophobic interactions. Three lines of data confirm this: DBCO-IgG liposomes and NGs have similar tropism for neutrophils in inflamed lungs; replacing DBCO with less hydrophobic SATAmaleimide conjugation $^{68}$ abrogates neutrophil tropism; and titrating down the amount of DBCO on IgG ratchets down neutrophil tropism of DBCO-IgG liposomes.

We showed that the mechanism by which neutrophils recognize NAPs is dependent on complement opsonization. While prior literature shows the importance of complement opsonization in nanoparticle uptake ${ }^{69}$, our observations suggest that the alternative pathway of complement responds to differences in supramolecular arrangement of protein.

Finally, we showed that some NAPs have anti-inflammatory properties. DBCO-IgG liposomes, without any cargo drug, provide dose-dependent reduction in protein and leukocyte extravasation into pulmonary alveoli in a model of the human lung disease ARDS. Neutrophil tracing showed that DBCO-IgG liposomes effect these benefits by decreasing neutrophil retention in inflamed pulmonary vasculature and reducing the neutrophils' ability to cross the pulmonary vascular barrier. DBCO-IgG liposomes decreased systemic and local inflammatory cytokines and chemokines, which may indicate effects on other cell types (for example, CXCL2 is secreted primarily by monocytes and macrophages) ${ }^{66,70}$. These anti-inflammatory effects may be viewed as side effects, since they imply effects on multiple cell types and signalling molecules (a full discussion of immunological implications is included in the Supplementary Information). Not all NAPs have anti-inflammatory effects (for example, NGs), so NAPs may be loaded with drugs, such as antibiotics, that have benefits in ALI.

Supramolecular arrangement of protein in nanoparticle structure predicts nanoparticle uptake in pulmonary marginated neutrophils during acute inflammation. Agglutinated protein is a motif in nanoparticle structure correlated with nanoparticle tropism for neutrophils. The NAPs identified in this study, and future NAPs based on parameters outlined here, could be untapped resources for diagnosis and treatment of devastating inflammatory disorders such as ALI.

\section{Online content}

Any methods, additional references, Nature Research reporting summaries, source data, extended data, supplementary information, acknowledgements, peer review information; details of author contributions and competing interests; and statements of data and code availability are available at https://doi.org/10.1038/ s41565-021-00997-y.

Received: 3 April 2020; Accepted: 31 August 2021;

Published online: 18 November 2021

\section{References}

1. Wright, H. L., Moots, R. J., Bucknall, R. C. \& Edwards, S. W. Neutrophil function in inflammation and inflammatory diseases. Rheumatology 49, 1618-1631 (2010).

2. Sônego, F. et al. Paradoxical roles of the neutrophil in sepsis: protective and deleterious. Front. Immunol. 7, 155 (2016).

3. Jickling, G. C. et al. Targeting neutrophils in ischemic stroke: translational insights from experimental studies. J. Cereb. Blood Flow. Metab. 35, 888-901 (2015).

4. Mehta, J. et al. Neutrophil function in ischemic heart disease. Circulation 79, 549-556 (1989).

5. Grommes, J. \& Soehnlein, O. Contribution of neutrophils to acute lung injury. Mol. Med. 17, 293-307 (2011). 
6. Summers, C. et al. Neutrophil kinetics in health and disease. Trends Immunol 31, 318-324 (2010).

7. Gee, M. H. \& Albertine, K. H. Neutrophil-endothelial cell interactions in the lung. Annu. Rev. Physiol. 55, 227-248 (1993).

8. Mayadas, T. N., Cullere, X. \& Lowell, C. A. The multifaceted functions of neutrophils. Annu. Rev. Pathol. 9, 181-218 (2014).

9. Mantovani, A., Cassatella, M. A., Costantini, C. \& Jaillon, S. Neutrophils in the activation and regulation of innate and adaptive immunity. Nat. Rev. Immunol. 11, 519-531 (2011).

10. Williams, A. E. \& Chambers, R. C. The mercurial nature of neutrophils: still an enigma in ARDS? Am. J. Physiol. Lung Cell. Mol. Physiol. 306, L217-L230 (2014)

11. Zemans, R. L. \& Matthay, M. A. What drives neutrophils to the alveoli in ARDS? Thorax 72, 1-3 (2017).

12. Summers, C. et al. Pulmonary retention of primed neutrophils: a novel protective host response, which is impaired in the acute respiratory distress syndrome. Thorax 69, 623-629 (2014).

13. Doerschuk, C. M. Mechanisms of leukocyte sequestration in inflamed lungs. Microcirculation 8, 71-88 (2001).

14. Worthen, G. S., Schwab, B., Elson, E. L. \& Downey, G. P. Mechanics of stimulated neutrophils: cell stiffening induces retention in capillaries. Science 245, 183-186 (1989).

15. Kuebler, W. M. \& Goetz, A. E. The marginated pool. Eur. Surg. Res 34, 92-100 (2002).

16. Doyle, N. A. et al. Neutrophil margination, sequestration, and emigration in the lungs of L-selectin-deficient mice. J. Clin. Invest. 99, 526-533 (1997).

17. Zhou, Z. et al. Heightened innate immune responses in the respiratory tract of COVID-19 patients. Cell Host Microbe 27, 883-890.e2 (2020).

18. Zeng, F. et al. Can we predict the severity of coronavirus disease 2019 with a routine blood test? Pol. Arch. Intern. Med. 130, 400-406 (2020).

19. Wang, D. et al. Clinical characteristics of 138 hospitalized patients with 2019 novel coronavirus-infected pneumonia in Wuhan, China. JAMA 323, 1061-1069 (2020).

20. Brenner, J. S. Nanomedicine for the treatment of acute respiratory distress syndrome. The 2016 ATS Bear Cage Award-winning proposal. Ann. Am. Thorac. Soc. 14, 561-564 (2017).

21. Brenner, J. S., Greineder, C., Shuvaev, V. \& Muzykantov, V. Endothelial nanomedicine for the treatment of pulmonary disease. Expert Opin. Drug Deliv. 12, 239-261 (2015).

22. Gao Smith, F. et al. Effect of intravenous $\beta$-2 agonist treatment on clinical outcomes in acute respiratory distress syndrome (BALTI-2): a multicentre, randomised controlled trial. Lancet 379, 229-235 (2012).

23. National, Heart, Lung, and Blood Institute Acute Respiratory Distress Syndrome (ARDS) Clinical Trials Network, et al. Randomized, placebo-controlled clinical trial of an aerosolized $\beta_{2}$-agonist for treatment of acute lung injury. Am. J. Respir. Crit. Care Med. 184, 561-568 2011).

24. Lee, P. Y., Wang, J.-X., Parisini, E., Dascher, C. C. \& Nigrovic, P. A. Ly6 family proteins in neutrophil biology. J. Leukoc. Biol. 94, 585-594 (2013).

25. Daley, J. M., Thomay, A. A., Connolly, M. D., Reichner, J. S. \& Albina, J. E. Use of Ly6G-specific monoclonal antibody to deplete neutrophils in mice. J. Leukoc. Biol. 83, 64-70 (2008).

26. Vij, N., Min, T., Bodas, M., Gorde, A. \& Roy, I. Neutrophil targeted nano-drug delivery system for chronic obstructive lung diseases. Nanomedicine 12, 2415-2427 (2016).

27. Bartneck, M. \& Wang, J. Therapeutic targeting of neutrophil granulocytes in inflammatory liver disease. Front. Immunol. 10, 2257 (2019).

28. Wang, Z., Li, J., Cho, J. \& Malik, A. B. Prevention of vascular inflammation by nanoparticle targeting of adherent neutrophils. Nat. Nanotechnol. $\mathbf{9}$, 204-210 (2014).

29. Chu, D., Gao, J. \& Wang, Z. Neutrophil-mediated delivery of therapeutic nanoparticles across blood vessel barrier for treatment of inflammation and infection. ACS Nano 9, 11800-11811 (2015).

30. Myerson, J. W. et al. Non-affinity factors modulating vascular targeting of nano- and microcarriers. Adv. Drug Deliv. Rev. 99, 97-112 (2016).

31. Mitragotri, S. \& Lahann, J. Physical approaches to biomaterial design. Nat. Mater. 8, 15-23 (2009)

32. Anselmo, A. C. \& Mitragotri, S. Impact of particle elasticity on particle-based drug delivery systems. Adv. Drug Deliv. Rev. 108, 51-67 (2017).

33. Ernsting, M. J., Murakami, M., Roy, A. \& Li, S.-D. Factors controlling the pharmacokinetics, biodistribution and intratumoral penetration of nanoparticles. J. Control. Release 172, 782-794 (2013).

34. Anselmo, A. C. \& Mitragotri, S. Cell-mediated delivery of nanoparticles: taking advantage of circulatory cells to target nanoparticles. J. Control. Release 190, 531-541 (2014)

35. Ferrer, M. C. C. et al. Icam-1 targeted nanogels loaded with dexamethasone alleviate pulmonary inflammation. PLoS ONE 9, e102329 (2014).

36. Myerson, J. W. et al. Flexible nanoparticles reach sterically obscured endothelial targets inaccessible to rigid nanoparticles. Adv. Mater. 30, e1802373 (2018)
37. Myerson, J. W. et al. Cross-linker-modulated nanogel flexibility correlates with tunable targeting to a sterically impeded endothelial marker. ACS Nano 13, 11409-11421 (2019).

38. Rahmani, S. et al. Long-circulating Janus nanoparticles made by electrohydrodynamic co-jetting for systemic drug delivery applications. J. Drug Target 23, 750-758 (2015).

39. Brenner, J. S. et al. Mechanisms that determine nanocarrier targeting to healthy versus inflamed lung regions. Nanomedicine 13, 1495-1506 (2017).

40. Lu, M. \& Munford, R. S. The transport and inactivation kinetics of bacterial lipopolysaccharide influence its immunological potency in vivo. J. Immunol. 187, 3314-3320 (2011).

41. Gregory, N. S. et al. An overview of animal models of pain: disease models and outcome measures. J. Pain 14, 1255-1269 (2013).

42. Ghasemlou, N., Chiu, I. M., Julien, J.-P. \& Woolf, C. J. CD11b+Ly6Gmyeloid cells mediate mechanical inflammatory pain hypersensitivity. Proc. Natl Acad. Sci. USA 112, E6808-E6817 (2015).

43. Li, J., Yu, S., Yao, P. \& Jiang, M. Lysozyme-dextran core-shell nanogels prepared via a green process. Langmuir 24, 3486-3492 (2008).

44. Bertsch, M. \& Kassner, R. J. Selective staining of proteins with hydrophobic surface sites on a native electrophoretic gel. J. Proteome Res. 2, 469-475 (2003)

45. Roh, K., Martin, D. C. \& Lahann, J. Biphasic Janus particles with nanoscale anisotropy. Nat. Mater. 4, 759-763 (2005).

46. Gregory, J. V. et al. Systemic brain tumor delivery of synthetic protein nanoparticles for glioblastoma therapy. Nat. Commun. 11, 5687 (2020)

47. Hwang, S. et al. Anisotropic hybrid particles based on electrohydrodynamic co-jetting of nanoparticle suspensions. Phys. Chem. Chem. Phys. 12, 11894-11899 (2010)

48. Lee, Y. et al. In vivo editing of macrophages through systemic delivery of CRISPR-Cas9-ribonucleoprotein-nanoparticle nanoassemblies. Adv. Ther. 2, 1900041 (2019).

49. Mout, R. et al. Direct cytosolic delivery of CRISPR/Cas9-ribonucleoprotein for efficient gene editing. ACS Nano 11, 2452-2458 (2017).

50. Lee, Y.-W. et al. Direct cytosolic delivery of proteins through coengineering of proteins and polymeric delivery vehicles. J. Am. Chem. Soc. 142, 4349-4355 (2020).

51. Russo, C. J. \& Passmore, L. A. Electron microscopy: ultrastable gold substrates for electron cryomicroscopy. Science 346, 1377-1380 (2014).

52. Mietzsch, M. et al. Comparative analysis of the capsid structures of aavrh.10, aavrh.39, and AAV8. J. Virol. 94, e01769-19 (2020).

53. Yu, X. et al. Cryo-EM structure of human adenovirus D26 reveals the conservation of structural organization among human adenoviruses. Sci. Adv 3, e1602670 (2017).

54. Drouin, L. M. \& Agbandje-McKenna, M. Adeno-associated virus structural biology as a tool in vector development. Future Virol. 8, 1183-1199 (2013).

55. Nemerow, G. R., Stewart, P. L. \& Reddy, V. S. Structure of human adenovirus Curr. Opin. Virol. 2, 115-121 (2012).

56. Pontillo, N., Pane, F., Messori, L., Amoresano, A. \& Merlino, A. Cisplatin encapsulation within a ferritin nanocage: a high-resolution crystallographic study. Chem. Commun. 52, 4136-4139 (2016).

57. Hood, E. D. et al. Vascular targeting of radiolabeled liposomes with bio-orthogonally conjugated ligands: single chain fragments provide higher specificity than antibodies. Bioconjug. Chem. 29, 3626-3637 (2018).

58. Dunkelberger, J. R. \& Song, W.-C. Complement and its role in innate and adaptive immune responses. Cell Res. 20, 34-50 (2010)

59. Soltis, R. D., Hasz, D., Morris, M. J. \& Wilson, I. D. The effect of heat inactivation of serum on aggregation of immunoglobulins. Immunology 36, 37-45 (1979).

60. Haihua, C., Wei, W., Kun, H., Yuanli, L. \& Fei, L. Cobra venom factor-induced complement depletion protects against lung ischemia reperfusion injury through alleviating blood-air barrier damage. Sci. Rep. 8, 10346 (2018).

61. Saguil, A. \& Fargo, M. Acute respiratory distress syndrome: diagnosis and management. Am. Fam. Physician 85, 352-358 (2012).

62. Fang, X. et al. Novel role for CFTR in fluid absorption from the distal airspaces of the lung. J. Gen. Physiol. 119, 199-207 (2002).

63. Tregay, N. et al. Use of autologous ${ }^{99 \mathrm{~m}}$ technetium-labelled neutrophils to quantify lung neutrophil clearance in COPD. Thorax 74, 659-666 (2019).

64. Brenner, J. S. et al. Red blood cell-hitchhiking boosts delivery of nanocarriers to chosen organs by orders of magnitude. Nat. Commun. 9, 2684 (2018)

65. Matute-Bello, G. et al. An official American Thoracic Society workshop report: features and measurements of experimental acute lung injury in animals. Am. J. Respir. Cell Mol. Biol. 44, 725-738 (2011).

66. De Filippo, K. et al. Mast cell and macrophage chemokines CXCL1/CXCL2 control the early stage of neutrophil recruitment during tissue inflammation. Blood 121, 4930-4937 (2013).

67. Meduri, G. U. et al. Persistent elevation of inflammatory cytokines predicts a poor outcome in ARDS. Plasma IL-1 beta and IL- 6 levels are consistent and efficient predictors of outcome over time. Chest 107, 1062-1073 (1995). 
68. Duncan, R. J., Weston, P. D. \& Wrigglesworth, R. A new reagent which may be used to introduce sulfhydryl groups into proteins, and its use in the preparation of conjugates for immunoassay. Anal. Biochem. 132, 68-73 (1983).

69. Szebeni, J., Muggia, F., Gabizon, A. \& Barenholz, Y. Activation of complement by therapeutic liposomes and other lipid excipient-based therapeutic products: prediction and prevention. Adv. Drug Deliv. Rev. 63, 1020-1030 (2011).
70. Qin, C.-C., Liu, Y.-N., Hu, Y., Yang, Y. \& Chen, Z. Macrophage inflammatory protein-2 as mediator of inflammation in acute liver injury. World $\mathrm{J}$. Gastroenterol. 23, 3043-3052 (2017).

Publisher's note Springer Nature remains neutral with regard to jurisdictional claims in published maps and institutional affiliations.

(C) The Author(s), under exclusive licence to Springer Nature Limited 2021 


\section{Methods}

Nanoparticle synthesis. NGs, crosslinked protein nanoparticles, charged protein nanoparticles, liposomes,and polystyrene nanoparticles were prepared as previously described ${ }^{36,43}$. Details of the synthesis for each type of nanoparticle are included in the Supplementary Information. Nanoparticles, proteins and bacteria were labelled with ${ }^{125} \mathrm{I}{ }^{131} \mathrm{I}$ or ${ }^{111} \mathrm{In}$ according to described methods ${ }^{57}$. Details of labelling techniques are provided in the Supplementary Information.

E. coli preparation. TOP10 E. coli (ThermoFisher \#C404002) were grown overnight in Terrific broth with ampicillin. Bacteria were heat-inactivated by a $20 \mathrm{~min}$ incubation at $60^{\circ} \mathrm{C}$, then fixed by overnight incubation in $4 \%$ paraformaldehyde. After fixation, bacteria were pelleted by centrifugation at $1,000 \mathrm{~g}$ for $10 \mathrm{~min}$. Pelleted bacteria were washed three times in PBS, before resuspension by pipetting. Bacterial concentration was verified by optical density at $600 \mathrm{~nm}$, before radiolabelling as described above. Bacteria were administered i.v. in mice ( $7.5 \times 10^{7}$ colony-forming units in a $100 \mu$ suspension per mouse).

\section{Nanoparticle and protein tracing in mice. Nanoparticle or protein} biodistributions were tested by i.v. injecting nanoparticles or protein (suspended to $100 \mu \mathrm{l}$ in PBS or $0.9 \%$ saline at a dose of $2.5 \mathrm{mg} \mathrm{kg}^{-1}$ with tracer quantities of radiolabelled material) in C57BL/6 male mice from Jackson Laboratories. For experiments tracing anti-Ly6G biodistributions to locate intravascular neutrophils, radiolabelled anti-Ly6G was administered i.v. at $0.1 \mathrm{mg} \mathrm{kg}^{-1}$. The quantity of injected radioactivity was measured by gamma counter (Perkin-Elmer) immediately before injection. To determine the nanoparticle masses for dosing, NGs and charged protein nanoparticles were prepared from reactants at known concentrations in synthetic methods involving no material loss; crosslinked protein nanoparticles were resuspended from weighed powder; polystyrene nanoparticles, ferritin and viral capsids were purchased at known concentrations. Liposomes were prepared from reactants at known concentrations and previous work with the same synthetic methods assessed low material losses during filtration and purification of liposomes s $^{57,71}$.

Biodistributions in naive mice were compared to biodistributions in injury models. Biodistribution data were collected at $30 \mathrm{~min}$ after nanoparticle or protein injection, unless otherwise stated. Blood was collected by vena cava draw and mice were killed by exsanguination and cervical dislocation. Organs were harvested and rinsed in saline, and blood and organs were examined for nanoparticle or protein retention by gamma counter. To calculate concentration in organs, quantity of retained radioactivity was normalized to organ weights.

For i.v. LPS, mice were anaesthetized with $3 \%$ isoflurane before retro-orbital injection of LPS from E. coli strain B4 at $2 \mathrm{mg} \mathrm{kg}^{-1}$ in $100 \mu \mathrm{PBS}$. After $5 \mathrm{~h}$, mice were anaesthetized with ketamine/xylazine $\left(10 \mathrm{mg} \mathrm{kg}^{-1} \mathrm{ketamine}, 100 \mathrm{mg} \mathrm{kg}^{-1}\right.$ xylazine, intramuscular administration) and before jugular vein nanoparticle or protein injection. For i.t. LPS, B4 LPS was administered to mice (anaesthetized with ketamine/xylazine) at $1 \mathrm{mg} \mathrm{kg}^{-1}$ in $50 \mu \mathrm{l}$ of PBS via tracheal catheter, followed by $100 \mu \mathrm{lof} \mathrm{air}^{71}$. NGs were injected $16 \mathrm{~h}$ after i.t. LPS and DBCO-IgG liposomes were injected 1,2 or $6 \mathrm{~h}$ after i.t. LPS. For footpad LPS, B4 LPS was administered at $1 \mathrm{mg} \mathrm{kg}^{-1}$ in $50 \mu \mathrm{l}$ PBS via footpad injection. NGs were injected i.v. 6 or $24 \mathrm{~h}$ after footpad LPS. For cardiogenic pulmonary oedema, mice were anaesthetized with ketamine/xylazine and administered propranolol in saline $\left(3 \mu \mathrm{g} \mathrm{ml}^{-1}\right)$ via jugular vein catheter at $83 \mu \mathrm{L} \mathrm{min}^{-1}$ over $120 \mathrm{~min}^{62}$, before i.v. NG injection. For localized footpad inflammation, mice were anaesthetized with $3 \%$ isoflurane and $20 \mu$ of CFA or $20 \mu \mathrm{l}$ of sham saline was injected subcutaneously in the central plantar region of the left hind $\mathrm{paw}^{42}, 6 \mathrm{~h}$ before i.v. NG injection.

Single-cell suspension flow cytometry. Single-cell suspensions were prepared from male C57BL/6 mouse lungs for flow cytometry. Fluorescent nanoparticles were administered at $2.5 \mathrm{mg} \mathrm{kg}^{-1} 30 \mathrm{~min}$ before the animals were killed and their lungs extracted. Mice were anaesthetized with ketamine/xylazine $\left(10 \mathrm{mg} \mathrm{kg}^{-1}\right.$ ketamine, $100 \mathrm{mg} \mathrm{kg}^{-1}$ xylazine, intramuscular administration) before installation of a tracheal catheter secured by suture. After the animals had been killed by vena cava exsanguination, lungs were perfused via the right ventricle with $\sim 10 \mathrm{ml}$ of cold PBS. Lungs were then infused via a tracheal catheter with $1 \mathrm{ml}$ of cold PBS solution with $5 \mathrm{U} \mathrm{ml}^{-1}$ dispase, $2.5 \mathrm{mg} \mathrm{ml}^{-1}$ collagenase I and $1 \mathrm{mg} \mathrm{ml}^{-1}$ of DNAse I. Immediately after infusion, the trachea was sutured shut while removing the tracheal catheter. Lungs with intact trachea were removed via thoracotomy and kept on ice before manual disaggregation.

Single-cell suspensions were also prepared from mouse feet. Feet were removed immediately following after the animals had been killed by cervical dislocation and $100 \mu \mathrm{l}$ of dispase/collagenase/DNAse was injected subcutaneously in the feet. Tissue was separated from the bones while the feet were held in $1 \mathrm{ml}$ of dispase/ collagenase/DNAse.

Disaggregated lung or foot tissue was aspirated in an additional $2 \mathrm{ml}$ of dispase/collagenase/DNAse and incubated at $37^{\circ} \mathrm{C}$ for $45 \mathrm{~min}$, vortexing every $10 \mathrm{~min}$. After addition of $1 \mathrm{ml}$ of fetal calf serum, tissue suspensions were strained through $100 \mu \mathrm{m}$ filters and centrifuged at $400 \mathrm{~g}$ for $5 \mathrm{~min}$. Pelleted material was resuspended in $10 \mathrm{ml}$ of cold ACK lysing buffer. The resulting suspensions were strained through a $40 \mu \mathrm{m}$ filter, incubated for $10 \mathrm{~min}$ on ice, and centrifuged at $400 \mathrm{~g}$ for $5 \mathrm{~min}$. The pelleted material was rinsed in $10 \mathrm{ml}$ of FACS buffer ( $2 \%$ fetal calf serum and $1 \mathrm{mM}$ EDTA in PBS). After $400 \mathrm{~g} / 5 \mathrm{~min}$ centrifugation, pellets were resuspended in $2 \%$ PFA in $1 \mathrm{ml} \mathrm{FACS}$ buffer for a $10 \mathrm{~min}$ room temperature incubation. Fixed cell suspensions were centrifuged at $400 \mathrm{~g}$ for $5 \mathrm{~min}$ and resuspended in $1 \mathrm{ml}$ of FACS buffer.

To stain fixed cells, $100 \mu \mathrm{l}$ aliquots of cell suspensions were pelleted at $400 \mathrm{~g}$ for $5 \mathrm{~min}$, then resuspended in labelled antibody diluted in FACS buffer (1:150 dilution for anti-Ly6G, APC-anti-CD31 or PE-anti-F480 antibodies and 1:500 dilution for anti-CD45 andtibodies). Samples were incubated with staining antibodies for $20 \mathrm{~min}$ at room temperature in the dark, diluted with $1 \mathrm{ml}$ of FACS buffer and pelleted at $400 \mathrm{~g}$ for $5 \mathrm{~min}$. Stained pellets were resuspended in $200 \mu \mathrm{l}$ of FACS buffer immediately before flow cytometry (BD Accuri). Data were gated to exclude debris and doublets. Controls with no stain, obtained from naive and i.v.-LPS-injured mice, established gates for negative/positive staining with FITC/ AlexFluor 488, PE, PerCP/Cy5.5 and APC/Alexa Fluor 647. Single-stain controls allowed automatic generation of compensation matrices in FCS Express software.

To analyse intravascular leukocyte populations in lungs, mice received i.v. FITC-anti-CD45 $5 \mathrm{~min}$ before they were killed. Populations of intravascular versus extravascular leukocytes were assessed by also staining fixed cell suspensions with PerCP-conjugated anti-CD45 and/or Alexa Fluor 647-conjugated anti-Ly6G. Comparing PerCP anti-CD45 with FITC anti-CD45 signal indicated intravascular versus extravascular leukocytes. Comparison of Alexa Fluor 647 anti-Ly6G, PerCP anti-CD45 and FITC anti-CD45 signal indicated intravascular versus extravascular neutrophils.

To characterize nanoparticle distribution among different cells in lungs or feet, fluorescent nanoparticles were administered at $2.5 \mathrm{mg} \mathrm{kg}^{-1}$ via jugular vein injection and circulated for $30 \mathrm{~min}$. Fixed single-cell suspensions were stained and coincidence of nanoparticle fluorescence with anti-CD45, anti-Ly6G, PE anti-CD31 or PE anti-F480 fluorescence was assessed.

In vitro neutrophil uptake of nanoparticles. Bone marrow was collected from pooled femurs of C57BL/6 mice. Neutrophils were isolated with the StemCell Technologies RoboSep Mouse Neutrophil Enrichment Kit by magnetic-bead-mediated depletion of non-neutrophils. To serum-treat NGs before incubation with neutrophils, $5 \times 10^{9}$ FITC-labelled NGs in $10 \mu$ PBS were incubated with $10 \mu \mathrm{l}$ serum for $1 \mathrm{~h}$ at $37^{\circ} \mathrm{C}$; then $1 \times 10^{6}$ neutrophils were rotated with $5 \times 10^{9} \mathrm{NGs}$ in $20 \mu \mathrm{PBS}$ for $15 \mathrm{~min}$ at $37^{\circ} \mathrm{C}$. For flow cytometry (BD Accuri C6), neutrophils were washed and stained with PerCP/Cy5.5 Ly6G antibodies (BD Biosciences, 1:100 dilution) and non-neutrophils were excluded from analysis via Ly6G staining (see Supplementary Fig. 27 for gating). NG fluorescence in neutrophils was quantified.

To probe the role of complement in neutrophil-nanoparticle interactions, complement was depleted from serum via two methods: heat treatment and CVF treatment. For heat treatment, serum was incubated at $56^{\circ} \mathrm{C}$ for $1 \mathrm{~h}$ and denatured proteins were removed by centrifugation at $10,000 \mathrm{~g}$ for $15 \mathrm{~min}$. For CVF treatment, 10 units CVF per $\mathrm{ml}$ serum were incubated for $1 \mathrm{~h}$ at $37^{\circ} \mathrm{C}$, then centrifuged at $10,000 \mathrm{~g}$ for $15 \mathrm{~min}$. Nanoparticle incubation with heat- and CVF-treated serum followed the same protocol described above for naive serum.

In vivo effects of complement on nanoparticle tropism for neutrophils. Mice were dosed with $100 \mu \mathrm{g}$ CVF per $\mathrm{kg}$ via intraperitoneal injection $24 \mathrm{~h}$ before NG administration or blood draw to test the in vivo effects of complement depletion on nanoparticle-neutrophil interactions. For experiments with both LPS and CVF, B4 LPS from E. coli was administered i.v. at $2 \mathrm{mg} \mathrm{kg}^{-1} 19 \mathrm{~h}$ after CVF and $5 \mathrm{~h}$ before i.v. NGs $\left(2.5 \mathrm{mg} \mathrm{kg}^{-1}\right)$, as described in Nanoparticle and protein tracing in mice.

Mass spectrometry profiles of protein coronae on nanoparticles. A $25 \mu \mathrm{l}$ volume of NGs or adenovirus capsids in a $5 \mathrm{mg} \mathrm{ml}^{-1}$ suspension were incubated with and equivalent volume of wild-type or CVF-treated (as above) mouse serum or saline sham for $1 \mathrm{~h}$ at $37^{\circ} \mathrm{C}$. Nanoparticles were pelleted by centrifugation and washed with $1 \mathrm{ml}$ PBS three times to separate from unbound serum proteins.

Opsonized and sham-opsonized nanoparticles were prepared for mass spectrometry analysis as follows. Samples were solubilized and digested with the iST kit (PreOmics GmbH) per the manufacturer's protocol. Nanoparticle pellets were resuspended, reduced and alykylated by addition of sodium deoxycholate buffer containing tris(2-carboxyethyl)phosphine and 2-chloroacetamide. The resulting suspensions were heated at $95^{\circ} \mathrm{C}$ for $10 \mathrm{~min}$. Proteins were enzymatically hydrolysed for $1.5 \mathrm{~h}$ at $37^{\circ} \mathrm{C}$ by endoproteinase Lys- $\mathrm{C}$ and trypsin. The resulting peptides were desalted, dried by vacuum centrifugation and reconstituted in $0.1 \%$ trifluoroacetic acid containing indexed retention time peptides (Biognosys Schlieren). Ultraperformance liquid chromatography-mass spectrometry data were obtained and analysed by published methods ${ }^{72,73}$, as detailed in the Supplementary Information.

SPECT/CT imaging. Imaging techniques, as described previously ${ }^{57}$, are detailed in the Supplementary Information. SPECT and CT data, in NIFTI format, were opened with ImageJ software (FIJI package) and processed for background removal, pseudocolour assignment and three-dimensional reconstruction, as detailed in the Supplementary Information. 
Nanoparticle administration in human lungs. Human lungs were obtained after organ harvest from transplant donors whose lungs were in advance deemed unsuitable for transplantation. Lungs were kept at $4{ }^{\circ} \mathrm{C}$ and used within $24 \mathrm{~h}$ of organ harvest. Lungs were inflated with low-pressure oxygen and oxygen flow was maintained at $0.81 \mathrm{~min}^{-1}$ for gentle inflation. Pulmonary artery subsegmental branches were endovascularly cannulated, then tested for retrograde flow by perfusing for $5 \mathrm{~min}$ with Steen solution containing a small amount of green tissue dye at $25 \mathrm{~cm} \mathrm{H}_{2} \mathrm{O}$ pressure. Pulmonary veins through which efflux of perfusate emerged were noted, allowing collection of solutions after passage through the lungs. A $2 \mathrm{ml}$ mixture of ${ }^{125} \mathrm{I}$-labelled NGs and ${ }^{131} \mathrm{I}$-labelled ferritin was injected through the arterial catheter. Approximately $100 \mathrm{ml}$ of 3\% BSA in PBS was passed through the same catheter to rinse unbound nanoparticles. A solution of green tissue dye was subsequently injected through the same catheter. The cannulated lung lobe was dissected into $\sim 1 \mathrm{~g}$ segments, which were evaluated for density of tissue dye staining. Segments were weighed, divided into 'high', 'medium', 'low' and 'null' levels of dye staining, and measured for ${ }^{131} \mathrm{I}$ and ${ }^{125} \mathrm{I}$ signal in a gamma counter.

For experiments with cell suspensions derived from human lungs (chosen for research use as above), single-cell suspensions were generously provided by Edward Morrisey at the University of Pennsylvania. Aliquots of 600,000 cells were pelleted at $400 \mathrm{~g}$ for $5 \mathrm{~min}$ and resuspended in $100 \mu \mathrm{l}$ FACs buffer containing different quantities of FITC-dextran NGs. Cells and NGs were incubated at room temperature for $60 \mathrm{~min}$ before twofold pelleting at $400 \mathrm{~g}$ with $1 \mathrm{ml}$ PBS washes. Cells were resuspended in $200 \mu \mathrm{l}$ FACS buffer for staining with APC anti-human CD45 (1:500 dilution, 20 min room temperature incubation). Cells were pelleted at $400 \mathrm{~g}$ for $5 \mathrm{~min}$ and resuspended in $200 \mu \mathrm{l}$ PBS for immediate analysis with flow cytometry (BD Accuri). Negative/positive NG or anti-CD45 signal was established by comparison to unstained cells. Single-stained controls indicated no spectral overlap between FITC-NG fluorescence and anti-CD45 APC fluorescence.

Effects of nanoparticles in nebulized LPS model. Mice were exposed to nebulized B4 LPS in a whole-body exposure chamber, with separate compartments for each mouse (MPC-3 AERO; Braintree Scientific). To maintain adequate hydration, mice were injected with $1 \mathrm{ml}$ sterile saline warmed to $37^{\circ} \mathrm{C}$, intraperitoneally, immediately before LPS exposure. LPS was reconstituted in PBS to $10 \mathrm{mg} \mathrm{ml}^{-1}$ and stored at $-80^{\circ} \mathrm{C}$ until use. Immediately before nebulization, LPS was thawed and diluted to $5 \mathrm{mg} \mathrm{ml}^{-1}$ with PBS. Then, $5 \mathrm{ml}$ of diluted LPS was aerosolized via a jet nebulizer connected to the exposure chamber (NEB-MED H, Braintree Scientific). Nebulization was performed until all liquid was nebulized ( $20 \mathrm{~min})$.

DBCO-IgG liposomes (20:1 DBCO:IgG, 2.5, 5,10 or $\left.30 \mathrm{mg} \mathrm{kg}^{-1}\right)$, bare liposomes $\left(30 \mathrm{mg} \mathrm{kg}^{-1}\right)$, NGs $\left(30 \mathrm{mg} \mathrm{kg}^{-1}\right)$ or saline sham were administered via retro-orbital injections of $100 \mu \mathrm{l}$ of suspension $2 \mathrm{~h}$ after LPS exposure. Mice were anaesthetized with $3 \%$ isoflurane to facilitate injections. Blood draws and BALF were collected $24 \mathrm{~h}$ after LPS exposure, as previously described and detailed in the Supplementary Information ${ }^{71}$. Mice were weighed before administration of nebulized LPS and before BALF and blood draws.

To stain for flow cytometry, BALF samples were centrifuged at $300 \mathrm{~g}$ for $4 \mathrm{~min}$, the supernatant was aspirated and $100 \mu \mathrm{l}$ of staining buffer $(1: 1,000$ APC-anti-CD45 or 1:150 Alexa Fluor 488-anti-Ly6G in FACS buffer) was added. Samples were stained for $30 \mathrm{~min}$ at room temperature in the dark, then $1 \mathrm{ml}$ of FACS buffer was added, samples were centrifuged at $300 \mathrm{~g}$ for $4 \mathrm{~min}$ and supernatant was aspirated. Cells were resuspended in $900 \mu \mathrm{l}$ of FACS buffer for flow cytometry analysis (BD Accuri). Forward scatter (area) versus side scatter (area) plots gated-out non-cellular debris and forward scatter (area) versus forward scatter (height) plots gated-out doublets. Unstained controls set gates for APC and Alexa Fluor 488 signal. Single-stained controls showed no spectral overlap between APC-anti-CD45 and Alexa Fluor 488-anti-Ly6G. CD45- and Ly6G-positive cells determined leukocyte and neutrophil concentrations, respectively.

To trace intravascular neutrophils after nebulized LPS treatment and $10 \mathrm{mg} \mathrm{kg}^{-1}$ DBCO-IgG liposome dosing, ${ }^{125} \mathrm{I}$-anti-Ly6G $\left(0.1 \mathrm{mg} \mathrm{kg}^{-1}\right)$ was administered 1 or $22 \mathrm{~h}$ after liposomes, and biodistributions were determined as described above. In mice treated with DBCO-IgG liposomes, blood was drawn into EDTA via the vena cava before exsanguination. Lungs and liver were removed after obtaining BALF and stored at $-80^{\circ} \mathrm{C}$. Blood was immediately evaluated with CBC measurements (Abaxis VetScan HM5). Blood remaining after CBC was centrifuged at $1,500 \mathrm{~g}$ for $10 \mathrm{~min}$ at $4{ }^{\circ} \mathrm{C}$ and plasma was extracted and stored at $-80^{\circ} \mathrm{C}$. Chemokine CXCL2 and cytokine IL- 6 were measured in BALF, plasma, and lung and liver homogenates according to published methods detailed in the Supplementary Information $^{74}$.

CD spectroscopy. Proteins were prepared in deionized and filtered water at concentrations of $0.155 \mathrm{mg} \mathrm{ml}^{-1}$ for human albumin, $0.2 \mathrm{mg} \mathrm{ml}^{-1}$ for hen lysozyme and $0.48 \mathrm{mg} \mathrm{ml}^{-1}$ for IgG. Albumin NPs, NGs and IgG-coated liposomes were diluted such that albumin, lysozyme and IgG concentrations in the suspensions matched concentrations of corresponding protein solutions. Protein and nanoparticle solutions were analysed in quartz cuvettes with $10 \mathrm{~mm}$ path length in an Aviv CD spectrometer. The instrument was equilibrated in nitrogen at $25^{\circ} \mathrm{C}$ for $30 \mathrm{~min}$ before use and samples were analysed with sweeps between 185 and $285 \mathrm{~nm}$ in $1 \mathrm{~nm}$ increments. Each data point was obtained after a $0.333 \mathrm{~s}$ settling time, with a $2 \mathrm{~s}$ averaging time. $\mathrm{CDNN}^{75}$ software deconvoluted $\mathrm{CD}$ data (expressed in millidegrees) via a neural network algorithm assessing alignment of spectra with library-determined spectra for helices, antiparallel sheets, parallel sheets, $\beta$ turns and random coils ${ }^{75}$

\section{8-Anilino-1-naphthalenesulfonic acid nanoparticle staining. 8-Anilino-} 1-naphthalenesulfonic acid (ANSA) at $0.06 \mathrm{mg} \mathrm{ml}^{-1}$ was mixed with lysozyme, human albumin or IgG at $1.5 \mathrm{mg} \mathrm{ml}^{-1}$ in PBS. For nanoparticle analysis, nanoparticle suspensions were prepared such that albumin, lysozyme and IgG concentrations in the suspensions matched the $1.5 \mathrm{mg} \mathrm{ml}^{-1}$ concentration of protein solutions. Protein or nanoparticles and ANSA were reacted at room temperature for $30 \mathrm{~min}$. Excess ANSA was removed from solutions by three centrifugations against $3 \mathrm{kDa}$ cut-off centrifugal filters (Amicon). After resuspension to original volume, ANSA-stained protein/nanoparticle solutions/ suspensions were examined for fluorescence (excitation, $375 \mathrm{~nm}$ ) and absorbance maxima corresponding to ANSA.

Histology. For imaging neutrophils in naive and i.v.-LPS-affected lungs, mice were given i.v. anti-Ly6G and killed $30 \mathrm{~min}$ later. Lungs were embedded in M1 medium, flash frozen and sectioned in $10 \mu \mathrm{m}$ slices. Sections were stained with Alexa Fluor 594-goat anti-rat secondary antibody (1:200 dilution) and imaged with epifluorescence microscopy. Similarly, rhodamine-dextran NGs were administered i.v. in i.v.-LPS mice $30 \mathrm{~min}$ before the mice were killed. Lungs were sectioned as above and stained with clone 1A8 anti-Ly6G antibody, followed by Alexa Fluor 350 -goat anti-rat secondary antibody (1:150 dilution), before epifluorescence and confocal imaging of NG and neutrophil fluorescence.

For histological verification of injury following nebulized LPS treatment, one set of injured mouse lungs and one set of naive lungs was infused intratracheally with $4 \%$ paraformaldehyde. The trachea was tied off and lungs and trachea were removed via thoracotomy. The lungs were suspended in $4 \%$ paraformaldehyde for overnight fixation before embedding in paraffin, sectioning and haematoxylin/ eosin staining.

Sections of human lungs were obtained after administration of rhodaminedextran NGs. NG-perfused and non-perfused tissue regions were harvested, embedded in M1 medium, flash frozen and sectioned in $10 \mu \mathrm{m}$ slices. NG fluorescence and tissue autofluorescence were detected with epifluorescence imaging.

Live lung imaging. A mouse was anaesthetized with ketamine/xylazine $5 \mathrm{~h}$ after i.v. LPS. A jugular vein catheter was placed for injection of NGs, anti-CD45 and fluorescent dextran. A patch of skin on the back of the mouse, around the juncture between the ribcage and the diaphragm, was denuded. The mouse was maintained on mechanical ventilation and the lungs were exposed via incision at the juncture between the ribs and the diaphragm. A coverslip affixed to a rubber O-ring was sealed to the incision by vacuum. The exposed lungs were focused under the objective using autofluorescence. With $100 \mathrm{~ms}$ exposure, channels corresponding to violet, green, near-red and far-red fluorescence were sequentially imaged. Rhodamine-dextran NGs $\left(2.5 \mathrm{mg} \mathrm{kg}^{-1}\right)$, Brilliant Violet-anti-CD45 $\left(0.8 \mathrm{mg} \mathrm{kg}^{-1}\right)$ and Alexa Fluor $647-70 \mathrm{kDa}$ dextran $\left(40 \mathrm{mg} \mathrm{kg}^{-1}\right)$ were injected via the jugular vein. Images were recorded for $30 \mathrm{~min}$ in SlideBook software and opened in Image) (FIJI distribution) for composition in movies with co-registration of the four fluorescent channels.

Animal and human study protocols. All animal studies were carried out in strict accordance with Guide for the Care and Use of Laboratory Animals as adopted by National Institutes of Health and approved by University of Pennsylvania Institutional Animal Care and Use Committee. All animal experiments used male C57BL/6 J mice, 6-8 weeks old, purchased from Jackson Laboratories. Mice were maintained at $20-25^{\circ} \mathrm{C}, 50 \% \pm 20 \%$ humidity, and on a $12 / 12 \mathrm{~h}$ dark/light cycle with food and water ad libitum.

Human lungs were obtained by the University of Pennsylvania Lung Biology Institute's Human Lung Tissue Bank (HLTB) from Gift of Life Donor Program (Philadelphia, PA, USA). Lungs provided to the HLTB were determined unsuitable for transplantation into a recipient, and would have been discarded if not used for our studies. Lungs provided by the HLTB for these studies are deidentified and cannot be linked to individual donors. Clinical staff procuring and distributing the tissue through the HLTB are not involved in the research after distribution of the deidentified tissue. Studies employing deidentified tissue from the HLTB were therefore determined by the University of Pennsylvania Institutional Review Board (IRB) to be IRB-exempt and were not considered human research subjects as defined by the Office of Human Research Protection of the National Institutes of Health. Deidentified patient data for human lungs (age, sex and cause of death) are tabulated in Supplementary Table 11.

Statistical analysis. Error bars indicate the standard error of the mean throughout Significance tests are described in captions. Statistical power was determined for statements of statistical significance and tabulated in the supplementary materials.

Reporting Summary. Further information on research design is available in the Nature Research Reporting Summary linked to this article. 


\section{Data availability}

All data supporting the findings of this study are presented graphically or in tables in the paper and Supplementary Information. Raw numerical imaging, flow cytometry, gamma counter, mass spectrometry and spectroscopy data provided graphically in this study are available as tabulated values from the corresponding author upon reasonable request.

\section{Code availability}

Linear discriminant and principal component analysis were completed with Gnu Octave 6.1.0 scripts adapted from https://www.bytefish.de/blog/pca_lda_with_ gnu_octave/ and are available in full in the Supplementary Information.

\section{References}

71. Hood, E. D. et al. Antioxidant protection by PECAM-targeted delivery of a novel NADPH-oxidase inhibitor to the endothelium in vitro and in vivo. J. Control. Release 163, 161-169 (2012).

72. Nesvizhskii, A. I., Keller, A., Kolker, E. \& Aebersold, R. A statistical model for identifying proteins by tandem mass spectrometry. Anal. Chem. 75, 4646-4658 (2003).

73. Bielow, C., Mastrobuoni, G. \& Kempa, S. Proteomics quality control: quality control software for maxquant results. J. Proteome Res. 15, 777-787 (2016).

74. Parhiz, H. et al. PECAM-1 directed re-targeting of exogenous mRNA providing two orders of magnitude enhancement of vascular delivery and expression in lungs independent of apolipoprotein E-mediated uptake. J. Control. Release 291, 106-115 (2018).

75. Böhm, G., Muhr, R. \& Jaenicke, R. Quantitative analysis of protein far UV circular dichroism spectra by neural networks. Protein Eng. 5, 191-195 (1992).

\section{Acknowledgements}

This research was supported by NIH R01HL125462 (V.R.M.). We acknowledge funding from the Defense Threat Reduction Agency (HDTRA-1-15-0045, J.L., V.R.M.). V.M.R. acknowledges NIH EB022641. J.W.M. was supported by NIH T32HL07915 while conducting this research. O.A.M.-C. received funding from the American Heart Association (19CDA345900001). L.L.M. was supported in part by NIH UL1TR001878. CD spectroscopy data were obtained at the University of Pennsylvania Biological Chemistry Resource Center. SPECT-CT images were obtained by Eric Blankenmyer in collaboration with the University of Pennsylvania Perelman School of Medicine Small Animal Imaging Facility. Single-cell suspensions prepared from human lungs were generously provided by Edward E. Morrisey's group at the University of Pennsylvania.

\section{Author contributions}

J.W.M, P.N.P, N.H., L.R.W., D.C.L, Y.-W.L., O.A.M.-C., E.D.H., T.S., J.V.G. and J.N. designed and prepared nanoparticles used in the study. J.W.M., P.M.G. and R.Y.K. prepared E. coli for tracing in mice. J.W.M., P.N.P., L.R.W., O.A.M.-C., L.L.M., P.M.G., I.J., J.N. and C.F.G. performed studies tracing nanoparticles in mice. J.W.M., P.N.P., M.H.Z., M.E.Z., J.W. and H.-Y.Z. performed studies of therapeutic efficacy. J.W.M., P.N.P. and L.T.F. performed studies tracing nanoparticles in human lungs. J.W.M., L.T.F. and K.M.R. performed studies tracing nanoparticle uptake in isolated cells. J.W.M., P.N.P., V.R.M. and J.S.B. analysed all data. The manuscript was written through contributions from all authors. All authors have given approval to the final version of the manuscript.

\section{Competing interests}

Findings in this study contributed to US provisional patent application number 62/943469, with J.W.M., P.N.P., L.R.W., V.R.M. and J.S.B. as inventors. The remaining authors declare no competing interests.

\section{Additional information}

Supplementary information The online version contains supplementary material available at https://doi.org/10.1038/s41565-021-00997-y.

Correspondence and requests for materials should be addressed to Jacob $S$. Brenner.

Peer review information Nature Nanotechnology thanks Edwin Chilvers, Bengt Fadeel, Gaurav Sahay and the other, anonymous, reviewer(s) for their contribution to the peer review of this work.

Reprints and permissions information is available at www.nature.com/reprints. 


\section{Reporting Summary}

Nature Research wishes to improve the reproducibility of the work that we publish. This form provides structure for consistency and transparency in reporting. For further information on Nature Research policies, see our Editorial Policies and the Editorial Policy Checklist.

\section{Statistics}

For all statistical analyses, confirm that the following items are present in the figure legend, table legend, main text, or Methods section.

n/a Confirmed

$\square$ The exact sample size $(n)$ for each experimental group/condition, given as a discrete number and unit of measurement

$\square$ \ A statement on whether measurements were taken from distinct samples or whether the same sample was measured repeatedly

$\square$ The statistical test(s) used AND whether they are one- or two-sided

$\square$ Only common tests should be described solely by name; describe more complex techniques in the Methods section.

Х $\square$ A description of all covariates tested

$\square$ \ A description of any assumptions or corrections, such as tests of normality and adjustment for multiple comparisons

$\square$ A full description of the statistical parameters including central tendency (e.g. means) or other basic estimates (e.g. regression coefficient)

AND variation (e.g. standard deviation) or associated estimates of uncertainty (e.g. confidence intervals)

$\varnothing$ For null hypothesis testing, the test statistic (e.g. $F, t, r$ ) with confidence intervals, effect sizes, degrees of freedom and $P$ value noted

Give P values as exact values whenever suitable.

Х $\square$ For Bayesian analysis, information on the choice of priors and Markov chain Monte Carlo settings

$\square \bigotimes$ For hierarchical and complex designs, identification of the appropriate level for tests and full reporting of outcomes

Х $\square$ Estimates of effect sizes (e.g. Cohen's $d$, Pearson's $r$ ), indicating how they were calculated

Our web collection on statistics for biologists contains articles on many of the points above.

\section{Software and code}

Policy information about availability of computer code

Data collection Flow cytometry data were acquired in BD Accuri C6 software. Histological imaging data were obtained with SlideBook 6 digital microscopy software. Gamma counter data were obtained as comma separated variable data tables through Perkin Elmer Wizard2 software. Dynamic light scattering and zeta potential data were collected in Malvern Zetasizer Nano software v3.30. Mass spectrometry data were obtained with Skyline AutoQC and Skyline Panorama. SPECT and CT data were obtained as NIFTI files with MIlabs integrated acquisition software. Ultraviolet/visible and fluorescence spectroscopy data were obtained with Molecular Devices Spectramax plate reader/spectrophotometer SoftMax Pro 7 control software. Circular dichroism spectra were obtained with Aviv control software v3.44.

Data analysis

Flow cytometry data were analyzed with FCS Express 6 Flow and FCS Express 7 Research. Histological, CT, and SPECT imaging data were processed in ImageJ (FIJ distribution, version 2.1.0/1.53c). Mass spectrometry data were analyzed in MaxQuant version 1.6.1.0 and Scaffold 4 with the Protein Prophet algorithm. Circular dichroism spectra were analyzed in CDNN (Circular Dichroism analysis using Neural Networks). All other data were saved as tabulated values in collection software (as listed above) for subsequent analysis in Microsoft Excel for Mac version 16.50. Bar, scatter, and line plots were all generated in Excel and arranged as figures in Microsoft PowerPoint for Mac version 16.50.

Statistical analyses were performed in Excel using the Real Statistics Resource Pack and in GraphPad Prism 8. Principal component analysis and linear discriminant analysis were performed in Gnu Octave 6.1.0, using scripts adapted from https://www.bytefish.de/blog/ pca_Ida_with_gnu_octave/, and made available in full in the supplementary materials. 
Policy information about availability of data

All manuscripts must include a data availability statement. This statement should provide the following information, where applicable:

- Accession codes, unique identifiers, or web links for publicly available datasets

- A list of figures that have associated raw data

- A description of any restrictions on data availability

All data supporting the findings of this study are presented graphically or in tables in the paper and supplementary materials. Raw numerical imaging, flow cytometry, gamma counter, mass spectrometry, and spectroscopy data provided graphically in this study are available as tabulated values from the corresponding author upon reasonable request.

\section{Field-specific reporting}

Please select the one below that is the best fit for your research. If you are not sure, read the appropriate sections before making your selection.

\section{Life sciences study design}

All studies must disclose on these points even when the disclosure is negative.

Sample size Sample size for biodistribution and flow cytometry experiments was set as $n=3$ biological replicates, based on anticipated effect size, anticipated standard error as determined by previous experience with radiotracer biodistributions and flow cytometry analysis of lungs, analysis of statistical power, and availability of reagent (i.e. nanoparticles, except where otherwise stated in the text). Where permitted by availability of reagent, additional replicates were obtained. Lysozyme-dextran nanogels, in particular, were available at all stages of the studies and additional replicates of in vivo biodistribution experiments with lysozyme-dextran nanogels were obtained alongside experiments with other nanoparticles to obtain direct comparisons of effect sizes.

For circular dichroism spectroscopy experiments, five replicate nanoparticle or protein suspensions or solutions were prepared for each tested group, based on observed error in initial measurements with albumin standards.

The number of mass spectrometry samples was constrained by availability of a shared mass spectrometry facility. Three nanoparticle-serum samples from each of three groups were tested as a minimum sample number allowing statistical tests on obtained data. Three control samples, with nanoparticles and no serum, were tested to verify that abundant serum peptides were absent in nanoparticle samples without serum. One reference sample, prepared from serum without nanoparticles, was tested to represent abundance of proteins in serum, as presented in insets in supplementary figure 30. Post-hoc, the tested sample numbers were verified as presenting statistically significant data on the relative response of complement proteins to the two nanoparticles under consideration.

Human lungs were available only on a limited basis, being constrained by availability of donor lungs that were not eligible for transplant and were deemed at low risk of being affected by infectious disease. It was determined that at least three human lung experiments should be performed with each type of tested nanoparticle. 125I-labeled lysozyme-dextran nanogels could be stably stored while waiting for available lungs without substantial nanoparticle instability or loss of radioactivity. 131l-labeled ferritin was subject to more rapid decay of radioactivity, so 131l-labeled ferritin was not available for all experiments with human lungs. Therefore, two experiments tested 125l-labeled lysozymedextran nanogels without 131-labeled ferritin, but sufficient numbers of experiments were performed to assure at least three measurements with 131--labeled ferritin. Post-hoc, statistical tests on data with the two particles verified a significant finding with the number of repetitions performed.

Given a relative lack of historical data to estimate anticipated effect size in experiments testing mouse responses to nebulized LPS injury, larger sample sizes were tested in initial experiments: $n=5$ biological replicates per group, repeated in three separate experiments. Analysis of statistical power in these experiments permitted reduction to $n=3$ biological replicates in subsequent dose-response studies. Complete blood count measurements were performed on samples from these same dose-response experiments. Complete blood count measurements in previous mouse studies led us to anticipate error in the data that would permit statistically conclusive measurements with three animals. ELISA measurements of IL-6 and CXCL2 were also taken on blood, tissue, and bronchoalveolar lavage from the same mice. Post-hoc analysis of significance and statistical power was applied to all measurements and supported all statements of significance in the manuscript.

Data exclusions No data were excluded from the presented data sets.

Replication Due to availability of imaging facilities, SPECT-CT imaging data were not replicated and the text reflects this, making no assertion of statistical significance for the imaging data and only making quantitative inference from gamma counter biodistribution data obtained with identical nanoparticles under identical biological conditions, for which analysis of statistical power is provided as described above. Imaging of fluorescent nanoparticles in human lungs also reflects an experiment with only one set of human lungs. Human lungs were infrequently available and statistically robust quantitative experiments with radiolabeled nanoparticles were prioritized over efforts to optimize fluorescent imaging of nanoparticles. No quantitative inference was drawn in the text on the basis of images of nanoparticles in human lungs: only confirmation that nanoparticles had indeed been injected in the imaged portion of the tissue. Finally, intravital imaging of nanoparticle uptake in leukocytes in inflamed lungs was only presented for one mouse. This experiment was designed to provide a demonstrative movie to pair with histological images and quantitative measurements of radioactivity from the same nanoparticles under similar biological conditions. No conclusions or quantifications were presented for intravital imaging data. All other experiments subject to attempts at replication were successfully repeated. Analyses of statistical power were compiled and tabulated in the supplementary materials for all statements of statistical significance and provide support for the replicability of all stated effects. For all stated effects in animals or human tissue, biological, rather than experimental replicates, were used to make statements of significance. Numbers and nature of replicates for all presented data are enumerated below: 
Anti-Ly6G biodistributions:

$\mathrm{n}=3$ naïve animals, $\mathrm{n}=3$ IV-LPS animals

Anti-Ly6G+IV-anti-CD45 flow cytometry:

$\mathrm{n}=3$ naïve animals, $\mathrm{n}=3$ IV-LPS animals

Anti-Ly6G histology:

$n=2$ naïve animals, $n=2$ IV-LPS animals

E. coli biodistributions:

$\mathrm{n}=4$ naïve animals, $\mathrm{n}=4$ IV-LPS animals

$130 \mathrm{~nm}$ NG biodistributions:

$\mathrm{n}=4$ naïve animals, $\mathrm{n}=8$ IV-LPS animals

Human albumin NP biodistributions:

$\mathrm{n}=3$ naïve animals, $\mathrm{n}=3$ IV-LPS animals

130 nm FITC-NG flow cytometry:

$\mathrm{n}=3$ naïve animals, $\mathrm{n}=3$ IV-LPS animals

Human albumin NP flow cytometry:

$\mathrm{n}=3$ naïve animals, $\mathrm{n}=3$ IV-LPS animals

$130 \mathrm{~nm}$ rhodamine-NG histology:

$\mathrm{n}=2$ naïve animals, $\mathrm{n}=2$ IV-LPS animals

$130 \mathrm{~nm}$ rhodamine-NG intravital imaging:

$\mathrm{n}=1$ IV-LPS animal

$130 \mathrm{~nm}$ NG biodistributions, intratracheal LPS:

$\mathrm{n}=4$ IT-LPS animals

$200 \mathrm{~nm}$ NG biodistributions, 5 minutes circulation:

$\mathrm{n}=4$ naïve animals, $\mathrm{n}=5 \mathrm{IV}$-LPS animals

$200 \mathrm{~nm}$ NG biodistributions, 15 minutes circulation:

$\mathrm{n}=4$ naïve animals, $\mathrm{n}=4$ IV-LPS animals

$200 \mathrm{~nm}$ NG biodistributions, 30 minutes circulation:

$\mathrm{n}=4$ naïve animals, $\mathrm{n}=4$ IV-LPS animals

$200 \mathrm{~nm}$ NG biodistributions, 60 minutes circulation:

$\mathrm{n}=4$ naïve animals, $\mathrm{n}=4$ IV-LPS animals

$200 \mathrm{~nm}$ NG biodistributions, 120 minutes circulation:

$\mathrm{n}=5$ naïve animals, $\mathrm{n}=4$ IV-LPS animals

$200 \mathrm{~nm}$ NG biodistributions, 240 minutes circulation:

$\mathrm{n}=5$ naïve animals, $\mathrm{n}=4$ IV-LPS animals

$200 \mathrm{~nm}$ NG biodistributions, 1440 minutes circulation:

$\mathrm{n}=5$ naïve animals, $\mathrm{n}=3$ IV-LPS animals

$130 \mathrm{~nm}$ NG biodistributions, footpad LPS ( 6 hours):

$\mathrm{n}=3$ footpad LPS animals

$130 \mathrm{~nm}$ NG biodistributions, footpad LPS (24 hours):

$\mathrm{n}=3$ footpad LPS animals

$200 \mathrm{~nm}$ NG biodistributions, footpad CFA:

$n=3$ sham-injured animals, $n=3$ CFA animals

$200 \mathrm{~nm}$ FITC-NG flow cytometry, footpad CFA:

$n=3$ sham-injured animals, $n=3$ CFA animals

NG/Lysozyme circular dichroism:

$\mathrm{n}=5 \mathrm{NG}$ samples, $\mathrm{n}=5$ lysozyme samples

$75 \mathrm{~nm}$ NG biodistributions:

$n=4$ naïve animals, $n=4$ IV-LPS animals

$275 \mathrm{~nm}$ NG biodistributions:

$\mathrm{n}=3$ naïve animals, $\mathrm{n}=4 \mathrm{IV}$-LPS animals

Albumin NPs/Albumin circular dichroism:

n=5 NP samples, $n=5$ lysozyme samples

Human albumin nanorod biodistributions:

$\mathrm{n}=3$ naïve animals, $\mathrm{n}=3$ IV-LPS animals

Bovine albumin NP biodistributions:

$\mathrm{n}=3$ naïve animals, $\mathrm{n}=3$ IV-LPS animals

Human hemoglobin NP biodistributions:

$n=5$ naïve animals, $n=4$ IV-LPS animals

Human transferrin NP biodistributions:

$\mathrm{n}=5$ naïve animals, $\mathrm{n}=5$ IV-LPS animals

Hen lysozyme NP biodistributions:

$\mathrm{n}=3$ naïve animals, $\mathrm{n}=3$ IV-LPS animals

PONI/E-GFP NP biodistributions:

$\mathrm{n}=4$ naïve animals, $\mathrm{n}=5$ IV-LPS animals

Gold/E-GFP NP biodistributions:

$\mathrm{n}=3$ naïve animals, $\mathrm{n}=3$ IV-LPS animals

Adenovirus capsid biodistributions:

$\mathrm{n}=5$ naïve animals, $\mathrm{n}=5$ IV-LPS animals

Adeno-associated virus capsid biodistributions:

$n=3$ naïve animals, $n=3$ IV-LPS animals

Horse spleen ferritin biodistributions:

$\mathrm{n}=5$ naïve animals, $\mathrm{n}=5$ IV-LPS animals

Bare PEG-liposome biodistributions:

$n=4$ naïve animals, $n=4$ IV-LPS animals

IgG-polystyrene biodistributions:

$n=4$ naïve animals, $n=4$ IV-LPS animals 
Bovine albumin biodistributions:

$\mathrm{n}=4$ naïve animals, $\mathrm{n}=4$ IV-LPS animals

Hen lysozyme biodistributions:

$n=3$ naïve animals, $n=4$ IV-LPS animals

Human transferrin biodistributions:

$n=3$ naïve animals, $n=4$ IV-LPS animals

SATA-IgG liposome biodistributions:

$\mathrm{n}=3$ naïve animals, $\mathrm{n}=3 \mathrm{IV}$-LPS animals

DBCO(20x)-IgG liposomes biodistributions:

$\mathrm{n}=3$ naïve animals, $\mathrm{n}=3$ IV-LPS animals

DBCO(10x)-IgG liposomes biodistributions:

$\mathrm{n}=4$ IV-LPS animals

$\mathrm{DBCO}(5 \mathrm{x})$-IgG liposomes biodistributions:

$n=3$ IV-LPS animals

$\operatorname{DBCO}(2.5 x)$-lgG liposomes biodistributions:

$\mathrm{n}=3$ IV-LPS animals

DBCO(20x)-IgG liposomes flow cytometry:

$\mathrm{n}=3$ naïve animals, $\mathrm{n}=3$ IV-LPS animals

DBCO(20x)-IgG liposomes biodistributions, IT-LPS (1 hour):

$\mathrm{n}=3$ IT-LPS animals

DBCO(20x)-IgG liposomes biodistributions, IT-LPS (2 hours):

$\mathrm{n}=3$ IT-LPS animals

DBCO(20x)-IgG liposomes biodistributions, IT-LPS (6 hours):

$\mathrm{n}=3$ IT-LPS animals

$\operatorname{DBCO}(20 x)-\lg G$ biodistributions:

$\mathrm{n}=4$ naïve animals, $\mathrm{n}=4 \mathrm{IV}$-LPS animals

DBCO-IgG circular dichroism:

n=5 samples for all five DBCO:IgG ratios

In vitro NG-neutrophil interactions:

$\mathrm{n}=18$ serum-NG preparations, $\mathrm{n}=18$ buffer-NG preparations

NG-neutrophil(naïve) interactions, different serum conditions:

$\mathrm{n}=10$ heat-treated serum-NG preparations

$n=11$ CVF-treated serum-NG preparations

$\mathrm{n}=8$ serum from CVF-treated mouse-NG preparations

NG-neutrophil(stimulated) interactions, different serum conditions:

$n=12$ naïve serum-NG preparations

$n=5$ heat-treated serum-NG preparations

$n=7$ CVF-treated serum-NG preparations

$\mathrm{n}=7$ serum from CVF-treated mouse-NG preparations

Mass spectrometry of opsonized NPs:

$\mathrm{n}=3 \mathrm{NG}$-serum preparations, $\mathrm{n}=3$ adenovirus-serum preparations

$n=3$ NG-PBS preparations, $n=3$ adenovirus-PBS preparations

$n=3$ NG-CVF-treated serum preparations

$n=1$ serum only sham preparation

$200 \mathrm{~nm}$ NG biodistributions, CVF-treated mice:

$n=4$ CVF-treated animals, $n=4$ CVF+LPS-treated animals

$\mathrm{CT}$ imaging of cardiogenic edema:

$\mathrm{n}=1$ naïve animal, $\mathrm{n}=1$ edematous animal

200 nm NG biodistributions, cardiogenic edema:

$\mathrm{n}=4$ cardiogenic pulmonary edema animals

$200 \mathrm{~nm}$ In-111-NG SPECT-CT imaging:

$\mathrm{n}=1$ naïve animal, $\mathrm{n}=1 \mathrm{IV}$-LPS animal

200 nm NG-human lung cell interactions:

$n=4$ NG-cell preparations at four different NG doses

$200 \mathrm{~nm} \mathrm{NG}$ /horse spleen ferritin radiotracing in human lungs:

$\mathrm{n}=5$ human lungs ( 3 with NGs+ferritin, 2 with NGs alone)

$200 \mathrm{~nm}$ rhodamine-NGs fluorescence in human lungs:

$\mathrm{n}=1$ human lungs

Histology of nebulized mouse lungs:

$\mathrm{n}=1$ naïve animal, $\mathrm{n}=1$ nebulized LPS animal

NP treatment effects on BALF in nebulized LPS:

$\mathrm{n}=5$ naïve animals:

$n=15$ sham-treated/injured animals

$\mathrm{n}=14$ injured animals treated with DBCO-IgG liposomes $(30 \mathrm{mg} / \mathrm{kg})$

$\mathrm{n}=5$ injured animals treated with NGs $(30 \mathrm{mg} / \mathrm{kg})$

$\mathrm{n}=5$ injured animals treated with bare PEG-liposomes $(30 \mathrm{mg} / \mathrm{kg})$

Dose-response for DBCO-IgG liposome effects:

$\mathrm{n}=3$ injured animals with $2.5 \mathrm{mg} / \mathrm{kg}, 5 \mathrm{mg} / \mathrm{kg}$, or $10 \mathrm{mg} / \mathrm{kg}$ liposomes

DBCO-IgG liposome effects on anti-Ly6G biodistributions:

$\mathrm{n}=3$ animals 1 hour post-liposomes, $\mathrm{n}=3$ animals 22 hours post-liposomes

Randomization For biodistribution and flow cytometry studies, mice from any given experimental group were taken from different cages and, likewise, different experimental conditions (e.g. different types of nanoparticles and naive vs. injured mice) were tested on each cage. As noted above, numbers of mice for biodistribution and flow cytometry were determined by expected error and availability of nanoparticles. Numbers of mice taken from each cage for experimental groups under consideration were determined according to total numbers allotted per group. Pseudorandom groups were therefore designed to assure that mice from any given experimental group (e.g., IV-LPS) were selected from the 
maximum number of available litters on any given day (usually three, sometimes two), with control animals (i.e., naïve or sham comparators) allocated similarly.

For studies testing treatment effects after nebulized LPS injury, mice for each treatment group were similarly distributed across multiple cages. Additionally, mice were exposed to nebulized LPS in a pie chamber, allowing simultaneous exposure of up to twelve mice. For each experiment, equivalent numbers of mice from each experimental group were exposed to LPS simultaneously, assuring that possible variations in injury conditions between LPS exposures would be controlled for in group-to-group results.

For circular dichroism experiments, day-to-day variation in measurements was considered for by taking a spectrum each day with an albumin standard, comparing to literature data for albumin circular dichroism spectra, then taking 5-10 measurements with 1-2 spectra per group on each day of experimentation. Stability of the albumin measurement was taken to signify day-to-day variability in measurement and error due to that variability was distributed evenly among tested groups.

For in vitro tests with nanoparticles, serum, and cultured neutrophils, multiple preparations of serum and neutrophils on multiple days were used to test the same nanoparticle species. That is, serum was prepared from mouse blood and neutrophils were prepared from mouse bone marrow in multiple preparations. To control for variability between these preparations, heat treatment, CVF treatment, and sham treatment were applied to the same serum and different serum conditions were tested on the same neutrophil preparations. Additionally, LPSstimulated and naïve neutrophils were tested side-by-side for the same neutrophil preparations, with that procedure repeated for multiple neutrophil preparations.

For the limited number of mass spectrometry measurements, the same serum preparation was tested against two different nanoparticles and with and without CVF treatment, in order to control for possible day-to-day/preparation-to-preparation variability in serum used to characterize opsonization of nanoparticles.

Human lung trials could not be randomized with the limited number of samples available. However, to control for variation between lungs in comparing human lung uptake of two different nanoparticles (ferritin and NGs), we used two different radiotracers to simultaneously trace ferritin and NGs in the same lungs.

Histological data making no quantitative comparisons and not subject to repetition was not randomized.

Blinding In biodistribution and nebulized LPS treatment experiments, one researcher prepared nanoparticles or protein solutions and another injected prepared suspensions/solutions, blinded to nanoparticle or protein characteristics. The blinded researcher obtained gamma counter measurements of biodistribution data or measurements of pulmonary edema/leukocyte extravasation, before conveying results to the unblinded researcher. Similar techniques were employed for dose-response effects of DBCO-IgG liposomes

Comparisons of naive and LPS-affected or complete Freund's adjuvant-treated mice were not blinded because gross observation of mouse behavior could distinguish injured from naive mice.

For flow cytometry experiments, only data characterizing distribution of NGs among cell types in the lungs followed the blinding procedure used for biodistribution studies: one researcher prepared a nanoparticle sample and provided it to a second researcher who performed animal experiments and flow cytometry measurements, while blinded to the nanoparticle characteristics. Other flow cytometry experiments were conducted when only one researcher was available with training in preparation of single cell suspensions from lungs who was also uniquely trained to prepare the nanoparticles being investigated. Flow cytometry data testing no nanoparticles, but simply comparing cell type distributions in naïve and IV-LPS lungs, was not blinded because, as above, gross observation of LPS-affected and naïve mice revealed differences between the two groups.

Histology experiments were not blinded because they were executed by a single researcher and no quantitative inference was drawn from histology data.

Data characterizing nanoparticles prior to biological experiments was not blinded because a single researcher was responsible for preparation of any given nanoparticle sample. These data included DLS measurements and circular dichroism spectroscopy.

Characterization of in vitro interactions between neutrophils and nanoparticles was not blinded because only one type of nanoparticle was being tested, with comparisons of different serum/neutrophil conditions being facilitated by a single researcher.

Mass spectrometry data characterizing serum proteins on nanoparticles was accumulated by a core facility, with the LC/MS operator obtaining the data blinded to the characteristics of the samples being examined.

Human lungs experiments were not blinded because the experimental setup required the expertise of a pulmonologist with whom the experimental design was discussed in order to optimize use of the donor lungs as a limited resource. Therefore, the pulmonologist handling the lungs during the experiment was aware of the types of nanoparticles being administered, if not the exact characteristics of the nanoparticles.

CT and SPECT-CT data were gathered in a core facility by a technician who was blinded to the identity of the agents administered to mice being imaged.

\section{Reporting for specific materials, systems and methods}

We require information from authors about some types of materials, experimental systems and methods used in many studies. Here, indicate whether each material, system or method listed is relevant to your study. If you are not sure if a list item applies to your research, read the appropriate section before selecting a response.

Materials \& experimental systems

\begin{tabular}{l|l}
\hline$n / a$ & Involved in the study \\
\hline & $\bigotimes$ Antibodies \\
$\searrow$ & $\square$ Eukaryotic cell lines \\
$\square$ & $\square$ Palaeontology and archaeology \\
$\square$ & $\square$ Animals and other organisms \\
$\searrow$ & $\square$ Clinical data \\
$\square$ & $\square$ Dual use research of concern
\end{tabular}

\begin{tabular}{l|l} 
Methods \\
\hline n/a & Involved in the study \\
$\square$ & $\square$ ChIP-seq \\
$\square$ & $\bigotimes$ Flow cytometry \\
$\square$ & $\square$ MRI-based neuroimaging
\end{tabular}


AlexaFluor 594 anti-rat secondary antibody: Reference PMID 28165452 (reference tested use of the secondary antibody for detection of anti-Ly6G antibody, as in our studies)

AlexaFluor 350 anti-rat secondary antibody: Reference PMID 27829467

Anti-Ly6G (mouse) clone 1A8: Reference PMID 25822788

PerCP/Cy5.5 anti-Ly6G: Reference PMID 8360469, validation by reactivity against isolated mouse neutrophils AlexaFluor 488 anti-Ly6G: Reference PMID 28659358, manufacturer indicates quality testing for flow cytometry applications AlexaFluor 647 anti-Ly6G: Reference PMID 29398651, manufacturer indicates quality testing for flow cytometry applications APC anti-CD45: Reference PMID 29057966, manufacturer indicates quality testing for flow cytometry applications PerCP/Cy5.5 anti-CD45: Reference PMID 29968710, manufacturer indicates quality testing for flow cytometry applications PE anti-F4/80: Reference PMID 28720115, manufacturer indicates quality testing for flow cytometry applications APC anti-CD31: Reference PMID 32094452

APC anti-CD45 (human): Reference PMID 29605184

\section{Animals and other organisms}

Policy information about studies involving animals; ARRIVE guidelines recommended for reporting animal research

Laboratory animals

All animal studies were conducted on 6-8 week old male C57BL/6 mice. purchased from Jackson Laboratories. Mice were maintained at $20-25^{\circ} \mathrm{C}, 50 \% \pm 20 \%$ humidity, and on a $12 / 12$ hour dark/light cycle with food and water ad libitum.

Wild animals

Field-collected samples

Ethics oversight

The study did not involve wild animals.

The study did not involve field-collected samples.

All animal studies were carried out in strict accordance with Guide for the Care and Use of Laboratory Animals as adopted by National Institute of Health and approved by University of Pennsylvania Institutional Animal Care and Use Committee (IACUC).

Note that full information on the approval of the study protocol must also be provided in the manuscript.

\section{Flow Cytometry}

\section{Plots}

Confirm that:

\The axis labels state the marker and fluorochrome used (e.g. CD4-FITC).

\The axis scales are clearly visible. Include numbers along axes only for bottom left plot of group (a 'group' is an analysis of identical markers).

\All plots are contour plots with outliers or pseudocolor plots.

$\bigotimes$ A numerical value for number of cells or percentage (with statistics) is provided.

\section{Methodology}

Sample preparation

Single cell suspensions were prepared from mouse lungs for flow cytometric analysis of cell type composition of the lungs and/or nanoparticle distribution among different cell types in the lungs. Nanoparticles were administered 30 minutes prior to sacrifice and lung extraction, as described for biodistributions above. C57BL/6 male mice were anesthetized with ketamine/ xylazine (10 mg/kg ketamine, $100 \mathrm{mg} / \mathrm{kg}$ xylazine, intramuscular administration) prior to installation of tracheal catheter secured by suture. After sacrifice by terminal exsanguination via the vena cava, lungs were perfused by right ventricle injection of $\sim 10 \mathrm{~mL}$ of cold PBS. The lungs were then infused via the tracheal catheter with $1 \mathrm{~mL}$ of a digestive enzyme solution consisting of $5 \mathrm{U} / \mathrm{mL}$ dispase, $2.5 \mathrm{mg} / \mathrm{mL}$ collagenase type I, and $1 \mathrm{mg} / \mathrm{mL}$ of DNAse I in cold PBS. Immediately after infusion, the trachea was sutured shut while removing the tracheal catheter. The lungs with intact trachea were removed via thoracotomy and kept on ice prior to manual disaggregation.

Single cell suspensions were also prepared from the feet of mice receiving plantar injections of complete Freund's adjuvant or saline. Feet were removed immediately following sacrifice by cervical dislocation and $100 \mu \mathrm{L}$ of digestive enzyme solution was injected subcutaneously in the feet. Tissue was separated from the bones, while the feet were held in $1 \mathrm{~mL}$ of digestive 
enzyme solution in a petri dish.

Disaggregated lung or foot tissue was aspirated in an additional $2 \mathrm{~mL}$ of digestive enzyme solution and incubated at $37^{\circ} \mathrm{C}$ for 45 minutes, with vortexing every 10 minutes. After addition of $1 \mathrm{~mL}$ of fetal calf serum, tissue suspensions were strained through $100 \mu \mathrm{m}$ filters and centrifuged at 400xg for 5 minutes. After removal of supernatant, the pelleted material was resuspended in $10 \mathrm{~mL}$ of cold ACK lysing buffer. The resulting suspensions were strained through $40 \mu \mathrm{m}$ filter and incubated for 10 minutes on ice. The suspensions were centrifuged at 400xg for 5 minutes and the resulting pellets were rinsed in 10 $\mathrm{mL}$ of FACS buffer ( $2 \%$ fetal calf serum and $1 \mathrm{mM}$ EDTA in PBS). After centrifugation at 400xg for 5 minutes, the rinsed cell pellets were resuspended in 2\% PFA in $1 \mathrm{~mL}$ FACS buffer for 10 minutes incubation. The fixed cell suspensions were centrifuged at 400xg for 5 minutes and resuspended in $1 \mathrm{~mL}$ of FACS buffer.

For analysis of intravascular leukocyte populations in naïve and inflamed lungs, mice received an intravenous injection of FITC-conjugated anti-CD45 antibody five minutes prior to sacrifice and preparation of single cell suspensions as described above. Populations of intravascular vs. extravascular leukocytes were assessed by subsequent stain of fixed cell suspensions with PerCP-conjugated anti-CD45 antibody and/or APC-conjugated clone $1 \mathrm{~A} 8$ anti-Ly6G antibody. To accomplish staining of fixed cells, $100 \mu \mathrm{L}$ aliquots of the cell suspensions described above were pelleted at 400xg for 5 minutes, then resuspended in labeled antibody diluted in FACS buffer (1:150 dilution for APC- conjugated anti-Ly6G antibody and 1:500 dilution for PerCPconjugated anti-CD45 antibody). Samples were incubated with staining antibodies for 20 minutes at room temperature in the dark, diluted with $1 \mathrm{~mL}$ of FACS buffer, and pelleted at 400xg for 5 minutes. Stained pellets were resuspended in $200 \mu \mathrm{L}$ of FACS buffer prior to immediate flow cytometric analysis on a BD Accuri flow cytometer. All flow cytometry data was gated to remove debris and exclude doublets. Control samples with no stain, obtained from naïve and IV-LPS-injured mice, established gates for negative/positive staining with FITC, PerCP, and APC. Single stain controls allowed automatic generation of compensation matrices in FCS Express software. Comparison of PerCP anti-CD45 signal with FITC anti-CD45 signal indicated intravascular vs. extravascular leukocytes. Comparison of APC anti-Ly6G signal with FITC anti-CD45 signal indicated intravascular vs. extravascular neutrophils, with PerCP and APC co-staining verifying identification of cells as neutrophils. Similar staining and analysis protocols enabled identification of fluorescent nanoparticle distribution among different cell types in the lungs.

For in vitro experiments with neutrophils, bone marrow was collected from pooled femorae of wild type C57BL/6 mice. Neutrophils were isolated with the StemCell Technologies RoboSep Mouse Neutrophil Enrichment Kit by magnetic beadmediated depletion of non-neutrophils. After incubation with fluorescent nanoparticles, neutrophils were washed and stained with PerCP/Cy5.5 Ly6G antibodies (BD Biosciences). In flow cytometric analysis (BD Accuri C6), non-neutrophils were excluded from analysis via Ly6G staining (gating strategy indicated in the Supplementary materials), and the amount of nanoparticle fluorescent signal in neutrophils was quantified.

For flow cytometric assessment of leukocyte content in bronchoalveolar lavage fluid, $0.8 \mathrm{~mL}$ of cold BAL buffer (0.5 mM EDTA in PBS) was injected into the lungs over $\sim 1$ min via tracheostomy and then aspirated from the lungs over $\sim 1$ min. Injections/ aspirations were performed three times for a total of $2.4 \mathrm{~mL}$ of fluid added to the lungs. Recovery of BAL fluid typically amounted to $\sim 2.0 \mathrm{~mL}$. BAL samples were centrifuged at 300xg for 4 minutes. The cell pellet was fixed for flow cytometry as follows. $333 \mu \mathrm{L}$ of $1.6 \%$ PFA in PBS was added to each sample. Samples were incubated in the dark at room temperature for 10 minutes, then $1 \mathrm{~mL}$ of BAL buffer was added. Samples were centrifuged at 400xg for 3min, the supernatant was aspirated, and $1 \mathrm{~mL}$ of FACS buffer ( $2 \%$ fetal calf serum and $1 \mathrm{mM}$ EDTA in PBS) was added. At this point, samples were stored at $4^{\circ} \mathrm{C}$ for up to 1 week prior to flow cytometry analysis. To stain BAL samples for flow cytometry, samples were centrifuged at 300xg for $4 \mathrm{~min}$, the supernatant was aspirated, and $100 \mu \mathrm{L}$ of staining buffer was added. Staining buffer used was a 1:1000 dilution of stock antibody solution (APC anti-mouse CD45; Alexa Fluor 488 anti-mouse Ly6G, Biolegend) into FACS buffer. Samples were incubated with staining antibody for 30 minutes at room temperature in the dark. To terminate staining, $1 \mathrm{~mL}$ of FACS buffer was added, samples were centrifuged at 300xg for 4 minutes, and supernatant was aspirated. Cells were resuspended in $900 \mu \mathrm{L}$ of FACS buffer and immediately analyzed via flow cytometry.

Instrument

Software

Cell population abundance

Gating strategy

\section{BD Accuri C6 or BD Accuri C6 Plus}

Flow cytometry data were acquired in BD Accuri C6 software. Flow cytometry data were analyzed with FCS Express 6 Flow and FCS Express 7 Research.

Abundance of CD45-positive and CD45/Ly6G double positive populations were dependent variables in all experiments with samples prepared from mouse organs. Relative abundance of CD45-positive and CD45/Ly6G double positive populations among cells gated for singlets is reported in the text, figures, and supplement for all tests. In experiments testing distribution of nanoparticles to different cell types and accumulation of leukocytes/neutrophils in the lungs, 50,000 cells in the singletgated population were counted for analysis. In experiments counting leukocytes/neutrophils in bronchoalveolar lavage fluid, 100 microliters of cell suspension (as described above) was subject to analysis and abundance was determined by antibody staining. For in vitro experiments with isolated neutrophils, neutrophil abundance was determined by Ly6G staining and Ly6G-negative events were discarded in final analysis.

FSC/SSC and FSC-A vs. FSC-H plots were gated to exclude cell aggregates and isolate cell singlets for staining analysis. For each experiment, gate limits for staining were determined by unstained and single-stained controls, with $<1 \%$ in the stainpositive population for unstained controls set as a threshold for staining gates. Cells from mouse feet, mouse lungs, bronchoalveolar lavage fluid, isolated neutrophils, and human lungs were assigned unique staining thresholds. 